\title{
Hypercapnia induces IL-1 $\beta$ overproduction via activation of NLRP3 inflammasome: implication in cognitive impairment in hypoxemic adult rats
}

Hong-Guang Ding 1,2,3, Yi-Yu Deng ${ }^{2}$, Ren-qiang Yang ${ }^{2}$, Qiao-Sheng Wang ${ }^{2}$, Wen-Qiang Jiang ${ }^{2}$, Yong-Li Han², Lin-Qiang Huang ${ }^{2}$, Miao-Yun Wen², Wen-Hong Zhong ${ }^{2}$, Xu-Sheng Li ${ }^{2}$, Fan Yang ${ }^{2}$ and Hong-Ke Zeng ${ }^{2,1^{*}}$

\begin{abstract}
Background: Cognitive impairment is one of common complications of acute respiratory distress syndrome (ARDS). Increasing evidence suggests that interleukin-1 beta (IL-1 $\beta$ ) plays a role in inducing neuronal apoptosis in cognitive dysfunction. The lung protective ventilatory strategies, which serve to reduce pulmonary morbidity for ARDS patients, almost always lead to hypercapnia. Some studies have reported that hypercapnia contributes to the risk of cognitive impairment and IL-1 $\beta$ secretion outside the central nervous system (CNS). However, the underlying mechanism of hypercapnia aggravating cognitive impairment under hypoxia has remained uncertain. This study was aimed to explore whether hypercapnia would partake in increasing IL-1 $\beta$ secretion via activating the NLRP3 (NLR family, pyrin domain-containing 3) inflammasome in the hypoxic CNS and in aggravating cognitive impairment.
\end{abstract}

Methods: The Sprague-Dawley (SD) rats that underwent hypercapnia/hypoxemia were used for assessment of NLRP3, caspase-1, IL-1 $3, \mathrm{BCl}-2$, Bax, and caspase-3 expression by Western blotting or double immunofluorescence, and the model was also used for Morris water maze test. In addition, Z-YVAD-FMK, a caspase-1 inhibitor, was used to treat BV-2 microglia to determine whether activation of NLRP3 inflammasome was required for the enhancing effect of hypercapnia on expressing IL-1 $\beta$ by Western blotting or double immunofluorescence. The interaction effects were analyzed by factorial ANOVA. Simple effects analyses were performed when an interaction was observed.

Results: There were interaction effects on cognitive impairment, apoptosis of hippocampal neurons, activation of NLRP3 inflammasome, and upregulation of IL-1 $\beta$ between hypercapnia treatment and hypoxia treatment. Hypercapnia + hypoxia treatment caused more serious damage to the learning and memory of rats than those subjected to hypoxia treatment alone. Expression levels of $\mathrm{BCl}-2$ were reduced, while that of Bax and caspase-3 were increased by hypercapnia in hypoxic hippocampus. Hypercapnia markedly increased the expression of NLRP3, caspase-1, and IL-1 $\beta$ in hypoxiaactivated microglia both in vivo and in vitro. Pharmacological inhibition of NLRP3 inflammasome activation and release of IL-1 $\beta$ might ameliorate apoptosis of neurons.

Conclusions: The present results suggest that hypercapnia-induced IL-1 $\beta$ overproduction via activating the NLRP3 inflammasome by hypoxia-activated microglia may augment neuroinflammation, increase neuronal cell death, and contribute to the pathogenesis of cognitive impairments.

Keywords: ARDS, Hypercapnia, Cognitive impairment, NLRP3 inflammasome, IL-1 $\beta$

\footnotetext{
* Correspondence: zenghongke@vip.163.com

${ }^{2}$ Department of Emergency and Critical Care Medicine, Guangdong General

Hospital and Guangdong Academy of Medical Sciences, 106 ZhongshanEr

Road, Guangzhou 510080, China

'Southern Medical University, 1838 North Guangzhou Avenue, Guangzhou

510515, China

Full list of author information is available at the end of the article
} 


\section{Background}

Permissive hypercapnia is a ventilation strategy to allow for an unphysiologically high-partial pressure of carbon dioxide $\left(\mathrm{PaCO}_{2}\right)$ included by reducing tidal volume, which serves to reduce pulmonary morbidity for acute respiratory distress syndrome (ARDS) patients [1]. Current guidelines recommend the concept of low tidal volume ventilation and permissive hypercapnia for patients with ARDS [2]. The benefits gained from the ventilation strategy are apparent; on the other hand, hypercapnia may present a risk to CNS. It has been reported in various studies that hypercapnia contributes to the risk of cognitive impairment $[3,4]$; indeed, half of all ARDS survivors develop cognitive impairments [5]. The incidence rate of cognitive impairment in ARDS survivors is over $70 \%$ at hospital discharge, over $46 \%$ at 1 year and over $20 \%$ at 2 years [6]. The mechanism of cognitive impairments in ARDS is still unclear. Some studies have found that a longer duration of hypoxemia was associated with cognitive impairment in ARDS survivors [7, 8]. It remains to be ascertained whether hypercapnia would aggravate cognitive impairment in ARDS patients with persistent hypoxemia.

It is well recognized that when activated by different external stimuli, microglia secrete a large number of pro-inflammatory cytokines (i.e., IL-1 $\beta$ ), and exposure of brain to hypoxemia represents one such stimulus, which is typical clinical presentation of ARDS. Previous studies have demonstrated that permissive hypercapnia may contribute to IL-1 $\beta$ secretion. In the lung of endotoxemic rats, IL-1 $\beta$ expression was significantly upregulated by hypercapnia treatment [9]. This suggests that hypercapnia may enhance the release of IL- $1 \beta$ in the hypoxic CNS. The expression levels of IL-1 $\beta$ [10] and its receptor [11] are comparatively higher in the hippocampus and are tightly linked to the deficits in hippocampusdependent memory [12]. In this connection, intraventricular infusion of the IL-1 receptor antagonist can block the deficits [13]. Increasing evidence suggests that IL- $1 \beta$ plays a pivotal role in inducing neuronal apoptosis in many neurodegenerative diseases [14]. It is well documented that $\mathrm{Bcl}-2$ protein, as a gatekeeper of the mitochondrial pathway of apoptosis, has significant antiapoptosis effect. However, Bax exhibits pro-apoptotic action. The ratio of Bax to Bcl-2 determines the downstream activation of caspase-3 [15]. Under pathological conditions, a large number of cell death may be caused by over-activation of apoptosis. In the CNS, overactivation of apoptosis can result in the death of a mass of neurons in the hippocampus CA1 regions and in cognitive impairment [16].

In the brain, pro-IL- $1 \beta$, as an inactive form of IL- $1 \beta$, is primarily produced by microglia in response to an inflammatory stimulus [17]. To exert its functions, pro-
IL- $1 \beta$ requires cleavage to an active form by caspase- 1 , which is regulated by NLRP3 inflammasome [18, 19]. The core structure of the NLRP3 inflammasome is formed by three proteins: NLRP3, pro-caspase-1, and the adaptor protein ASC (apoptosis-associated specklike protein containing a CARD). Extracellular ATP, urate, potassium efflux, or production of reactive oxygen species (ROS) can trigger the NLRP3 inflammasome, which would result in activation of caspase- 1 and processing of pro-IL- $1 \beta$ to IL-1 $\beta[20,21]$. It has remained to be explored whether hypercapnia has the effect of activating the NLRP3 inflammasome specifically in the activated microglia in production of IL-1 $\beta$.

In the present study, we hypothesized that hypercapnia may aggravate the cognitive impairment in adult male Sprague-Dawley (SD) rats with hypoxemia. It was surmised that hypercapnia may exert its effect through increasing IL-1 $\beta$ secretion, and via activating the NLRP3 inflammasome, it can cause excessive apoptosis of hippocampal neurons.

\section{Methods}

\section{Animals and experimental groups}

Adult male Sprague-Dawley (SD) rats weighing 250-300 g were provided by Institute of Laboratory Animal Science of Jinan University. The rats $(n=128)$ were randomly divided into four groups ( $n=32$ rats each): sham-operated group (abbreviated $\mathrm{S}$ group), exposed to the air; hypercapnia group, exposed to $\mathrm{CO}_{2}$ concentrations of $5 \%$ of the gas mixture to maintain $\mathrm{pH}$ at 7.2-7.25; hypoxemia group, exposed to $\mathrm{O}_{2}$ concentrations of $16 \%$ to maintain partial pressure of oxygen $\left(\mathrm{PaO}_{2}\right)$ at around $60 \mathrm{mmHg}$. In the hypercapnia + hypoxemia group (abbreviated HH group), a gas mixture of $5 \% \mathrm{CO}_{2}$ containing $16 \% \mathrm{O}_{2}$ was used to maintain $\mathrm{pH}$ at 7.2-7.25 and $\mathrm{PO}_{2}$ at around $60 \mathrm{mmHg}$.

\section{Rat model of hypercapnia/hypoxemia}

Before the experiments, all rats were fasted overnight but allowed free access to water. The rats were anesthetized with an intraperitoneal injection of $30 \mathrm{mg} / \mathrm{kg}$ pentobarbital sodium (Merck, Darmstadt, Germany; cat. no.1063180500) and were mechanically ventilated for $3 \mathrm{~h}$ using a small-animal ventilator (SAR-1000, CWE, Ardmore, PA, USA). The tidal volume was set at $9 \mathrm{ml} /$ $\mathrm{kg}$ body weight, the respiratory rate was 45 breaths/min, and inspiratory to expiratory ratio was 1:1 [22]. Mechanical ventilation was performed using a gas tank containing either room air (S group), a gas mixture containing $5 \% \mathrm{CO}_{2}, 21 \% \mathrm{O}_{2}, 74 \% \mathrm{~N}_{2}$ (Hypercapnia group), $16 \% \mathrm{O}_{2}$, $84 \% \mathrm{~N}_{2}$ (Hypoxemia group), or $5 \% \mathrm{CO}_{2}, 16 \% \mathrm{O}_{2}$, and $79 \% \mathrm{~N}_{2}$ (HH group). Two gas monitors (P110, P120, Biospherix, Lacona, NY, USA) were used to monitor the concentrations of $\mathrm{CO}_{2}$ and $\mathrm{O}_{2}$ in the respiratory circuit. 
The left femoral artery was cannulated with a selfmade infusion tube (a PE 10 cannula and an indwelling needle connected with parafilm) to collect arterial blood samples. A Blood Gas/Electrolyte Analyzer (Model 5700, IL, San Diego, CA, USA) was used to measure $\mathrm{PO}_{2}$, $\mathrm{PCO}_{2}$, and $\mathrm{pH}$ of the arterial blood samples. The caudal vein was cannulated to enable an infusion of $0.9 \%$ saline for maintenance fluid. All surgical incisions were infiltrated with $0.25 \%$ lidocaine. The rats used for the following experiments (Morris water maze test, immunofluorescence staining, and Western blotting analysis) were mechanically ventilated without any kind of invasive manipulation. The rectal temperature was continuously measured and maintained at $37{ }^{\circ} \mathrm{C}$ using a heating lamp.

\section{Morris water maze test}

Morris water maze (MWM) test was conducted to assess hippocampus-dependent spatial learning and memory functions in rodents [23]. The apparatus consisted of a $200 \mathrm{~cm}$ in diameter circular pool and a camera, which was placed above the pool and connected to a computer to track the behavior of rats. The pool was filled with warm water $\left(25 \pm 1{ }^{\circ} \mathrm{C}\right)$ and artificially divided into four equal quadrants. An escape platform, $9 \mathrm{~cm}$ in diameter, was permanently placed in one quadrant and $1 \mathrm{~cm}$ under the water level. Twenty-four hours after the treatment, each rat was allowed to swim in the water for $120 \mathrm{~s}$ to familiarize with the environment and task. At 48 and $72 \mathrm{~h}$ after treatment, rats were tested in the MWM task. Time taken by rats to reach the platform was recorded as latency time. If the rat failed to find the platform in $120 \mathrm{~s}$, latency time was recorded as $120 \mathrm{~s}$. The rat was manually guided to the platform and was allowed to stay on it for $60 \mathrm{~s}$.

\section{Microglial culture and treatment}

BV-2 microglial cells (CHI Scientific, Wuxi, China; cat. no. 7-1502) were cultured in Dulbecco's Modified Eagle Medium (DMEM) high glucose (Gibco/Thermo Fisher, Grand Island, NY, USA; cat. no. 8117046) supplemented with $10 \%$ fetal bovine serum (FBS) (Capricorn Scientific $\mathrm{GmbH}$, Ebsdorfergrund, Germany; cat. no. FBS-52A) at $37{ }^{\circ} \mathrm{C}$ in a humidified incubator with $5 \% \mathrm{CO}_{2} / 95 \%$ air. The cells were divided into five groups: control group, exposed to $20 \% \mathrm{O}_{2}+5 \% \mathrm{CO}_{2}$; high concentration of carbon dioxide group ( $\mathrm{HC}$ group), exposed to $20 \% \mathrm{O}_{2}+$ $15 \% \mathrm{CO}_{2}$; hypoxia group, exposed to $0.2 \% \mathrm{O}_{2}+5 \% \mathrm{CO}_{2}$; hypoxia + $\mathrm{HC}$ group, exposed to $0.2 \% \mathrm{O}_{2}+15 \% \mathrm{CO}_{2}$; hypoxia + HC + Z-YVAD-FMK group, treated with ZYVAD-FMK (10 $\mu \mathrm{M})$ [24] (ApexBio, Boston, MA, USA; cat. no. A8955) for $30 \mathrm{~min}$ before being exposed to $0.2 \%$ $\mathrm{O}_{2}+15 \% \mathrm{CO}_{2}$. The treated cells from different groups were incubated in an air-tight chamber, in which the $\mathrm{O}_{2}$ and $\mathrm{CO}_{2}$ concentrations were controlled by a Carbon Dioxide and Oxygen Controller (ProOx C21, Biospherix, Lacona, NY, USA). A Blood Gas/Electrolyte Analyzer (Model 5700, IL, San Diego, CA, USA) was used to measure $\mathrm{PO}_{2}, \mathrm{PCO}_{2}$, and $\mathrm{pH}$ of supernatants.

\section{Preparation of BV-2 conditioned medium}

Microglia-conditioned medium was prepared according to the procedure reported previously [25]. BV-2 microglial cells were cultured in $75 \mathrm{~cm}^{2}$ culture flasks with DMEM/F12 medium (Gibco/Thermo Fisher, Grand Island, NY, USA; cat. no. C11330500BT) supplemented with $10 \%$ FBS. The cells were washed with PBS to eliminate sera and incubated with DMEM/F12 medium without FBS. Five different kinds of conditioned medium were prepared: BV-2 conditioned medium (CM), BV-2 cells were exposed to $20 \% \mathrm{O}_{2}+5 \% \mathrm{CO}_{2}$ for $24 \mathrm{~h}$; BV-2 conditioned medium + high concentration of carbon dioxide $(\mathrm{CM}+\mathrm{HC})$ : $\mathrm{BV}-2$ cells were exposed to $20 \% \mathrm{O}_{2}+15 \%$ $\mathrm{CO}_{2}$ for $24 \mathrm{~h}$; BV-2 conditioned medium + hypoxia (CM + hypoxia): $\mathrm{BV}-2$ cells were exposed to $0.2 \% \mathrm{O}_{2}+5 \% \mathrm{CO}_{2}$ for $24 \mathrm{~h}$; BV-2 conditioned medium + hypoxia + high concentration of carbon dioxide (CM + hypoxia $+\mathrm{HC})$ : $\mathrm{BV}-2$ cells were exposed to $0.2 \% \mathrm{O}_{2}+15 \% \mathrm{CO}_{2}$ for $24 \mathrm{~h}$; BV-2 conditioned medium with Z-YVAD-FMK pretreatment + hypoxia + high concentration of carbon dioxide $(\mathrm{CM}+$ hypoxia $+\mathrm{HC}+\mathrm{Z})$ : BV-2 cells were treated with $\mathrm{Z}$ YVAD-FMK $(10 \mu \mathrm{M})$ for $30 \mathrm{~min}$, the medium was then discarded and the microglial cultures were washed with PBS twice. Following this, $10 \mathrm{ml}$ DMEM/F12 medium without FBS was added. The cells were exposed to $0.2 \%$ $\mathrm{O}_{2}+15 \% \mathrm{CO}_{2}$ for $24 \mathrm{~h}$. The conditioned medium was filtered through $0.22 \mu \mathrm{m}$ syringe filters and used immediately.

\section{Primary cultures of neurons and treatment with BV-2 conditioned medium}

Primary neuronal cell cultures were prepared as described previously [26]. Briefly, the hippocampus was isolated from the brain of newborn SD rats (1 day old). The hippocampus was minced into tiny particles and digested with $0.125 \%$ trypsin for $10 \mathrm{~min}$ at $37{ }^{\circ} \mathrm{C}$, then neutralized with fetal bovine serum (FBS), and finally centrifuged at $1100 \mathrm{rpm}$ for $5 \mathrm{~min}$. The cells were resuspended in DMEM/F12 medium containing 10\% FBS and plated into poly-L-lysine (Sigma, St. Louis, MO, USA; cat. no. P1399) coated flasks. Cells were incubated at $37{ }^{\circ} \mathrm{C}$ in a humidified incubator with $5 \% \mathrm{CO}_{2} / 95 \%$ air for $6 \mathrm{~h}$. Then, the medium was changed and cells were incubated in neurobasal medium (Gibco/Thermo Fisher, Grand Island, NY, USA; cat. no. 121103049) containing 2\% B27 (Gibco/Thermo Fisher, Grand Island, NY, USA; cat. no. 17504044) and 1\% glutamine (Sigma, St. Louis, MO, USA; cat. no. G3126); half of the medium was 
replaced with neurobasal containing 2\% B27 without glutamine 3 days later. Thereafter, they were incubated for $3 \mathrm{~h}$ in the following conditions: BV-2 conditioned medium (CM group), BV-2 conditioned medium + high concentration of carbon dioxide (CM $+\mathrm{HC}$ group), BV-2 conditioned medium + hypoxia (CM + hypoxia group), BV2 conditioned medium + hypoxia + high concentration of carbon dioxide ( $\mathrm{CM}+$ hypoxia $+\mathrm{HC}$ group), BV-2 conditioned medium with Z-YVAD-FMK pretreatment + hypoxia + high concentration of carbon dioxide (CM + hypoxia $+\mathrm{HC}+\mathrm{Z}$ group). The purity of neurons was assessed by immunocytochemical staining using MAP-2 (a marker of neurons) (Abcam, Cambridge, MA, USA; cat. no. ab32454) and DAPI, a nuclear marker of all cells. The purity of primary neuron cultures was above $95 \%$ in this study.

\section{Western blotting analysis}

Total proteins from hippocampus tissue, BV-2 cells and primary neuronal cells $(n=4$ for each group) were extracted using a Total Protein Extraction Kit (BestBio, Shanghai, China; cat. no. BB-3101). Protein concentration was measured using a BCA Protein Assay kit (Bioworld Technology, St. Louis Park, MN, USA; cat. no. BD0028). Briefly, the protein samples were heated at $95{ }^{\circ} \mathrm{C}$ for $5 \mathrm{~min}$. Equal amounts of protein was separated in a $12 \%$ SDS polyacrylamide gel and blotted onto PVDF membranes. Membranes were blocked with $5 \%$ non-fat milk for $1 \mathrm{~h}$ at room temperature and then incubated with primary antibodies overnight at $4{ }^{\circ} \mathrm{C}$ with light shaking. The primary antibodies used were as follows: IL-1 $\beta$ (applied to tissue, 1:1000, Abcam, Cambridge, MA, USA; cat. no. ab9787), IL-1 $\beta$ (applied to cells, 1:1000, Chemicon International, Temecula, CA, USA; cat. no. AB1832P), caspase-1 (1:1000, Abcam, Cambridge, MA, USA; cat. no. ab1872), NLRP3 (1:1000, Abcam, Cambridge, MA, USA; cat. no. ab214185), Bax (1:1000, Cell Signaling Technology, Danvers, MA, USA; cat. no. 14796), Bcl-2 (1:1000, Abcam, Cambridge, MA, USA; cat. no. ab194583), caspase-3 (1:1000, Cell Signaling Technology, Danvers, MA, USA; cat. no. 9664S). On the following day, the membranes were incubated with the horseradish peroxidase (HRP)-conjugated secondary antibodies for $2 \mathrm{~h}$ at $4{ }^{\circ} \mathrm{C}$. The secondary antibody was goat anti-rabbit IgGHRP (1:3000, Cell Signaling Technology; cat. no. 7074S). Protein was visualized with enhanced chemiluminescence using a chemiluminescence kit (Millipore, Billerica, MA, USA; cat. no. WBKLS0500), and images were generated by an imaging densitometer (ImageQuant LAS 500, GE Healthcare Bio-Sciences AB, Uppsala, Sweden). The relative density was quantified by FluorChem 8900 software (version 4.0.1, Alpha Innotech Corporation, San Leandro, CA, USA). In addition, GAPDH was used as the control.

\section{Immunofluorescence staining}

Double immunofluorescence staining was carried out to detect IL-1 $\beta$ expression in microglia and caspase-3 expression in neurons in hippocampus tissue. After $3 \mathrm{~h}$ of treatment, four rats from each group were randomly selected. The rats were deeply anesthetized with pentobarbital sodium and transcardially perfused with ice-cold $0.9 \%$ saline rapidly followed by $4 \%$ paraformaldehyde. The brain was removed, and frozen coronal sections of $10 \mu \mathrm{m}$ thickness were cut. The sections were blocked with 5\% normal donkey serum for $1 \mathrm{~h}$ at room temperature. After rinsing with phosphate-buffered saline (PBS), the brain sections were incubated with the following primary antibodies: IL-1 $\beta$ (1:100, Abcam, Cambridge, MA, USA; cat. no. ab9787) and Iba1 (1:100, Abcam, Cambridge, MA, USA; cat. no. ab15690), caspase-3 (1:100, Cell Signaling Technology, Danvers, MA, USA; cat. no. 9664S), and NeuN (1:100, Millipore, Billerica, MA, USA; cat. no. 2766373) at $4{ }^{\circ} \mathrm{C}$ for overnight. On the following day, the sections were incubated with the secondary antibodies Alexa Fluor 555 Donkey Anti-Rabbit IgG $(\mathrm{H}+\mathrm{L})$ (1:100, Invitrogen Life Technologies, Carlsbad, CA, USA; cat. no. A31572), Alexa Fluor $^{\oplus} 488$ donkey anti-mouse IgG (1:100, Invitrogen Life Technologies, Carlsbad, CA, USA; cat. no. A21202) for $1 \mathrm{~h}$ at room temperature. Finally, the sections were mounted using Fluoroshield with DAPI (Sigma, St. Louis, MO, USA; cat. no. F6057) and detected with a fluorescence microscope (Olympus DP73 Microscope, Olympus, Tokyo, Japan).

After $24 \mathrm{~h}$ of treatment, cover slips with adherent BV2 cells were fixed in $4 \%$ paraformaldehyde for $20 \mathrm{~min}$, blocked by $5 \%$ normal donkey serum for $30 \mathrm{~min}$ at room temperature. Subsequently, the cover slips were incubated at $4{ }^{\circ} \mathrm{C}$ overnight with the primary antibodies: IL-1 $\beta$ (1:100, Chemicon International, Temecula, CA, USA; cat. no. AB1832P), NLRP3 (1:100, Abcam, Cambridge, MA, USA; cat. no. ab4207), caspase-1 (1:100, Abcam, Cambridge, MA, USA; cat. no. ab1872). On the next day, the cover slips were incubated with the secondary antibodies Alexa Fluor 555 Donkey Anti-Rabbit IgG (1:100, Invitrogen Life Technologie, Carlsbad, CA, USA; cat. no. A31572), Alexa Fluor 488 Donkey Anti-Goat IgG (1:100, Abcam, Cambridge, MA, USA; cat. no. ab150129), or lectin. Finally, all cover slips were mounted using Fluoroshield with DAPI (Sigma, St. Louis, MO, USA; cat. no. F6057) and detected with a fluorescence microscope (Olympus DP73 Microscope, Olympus, Tokyo, Japan).

\section{Statistical analysis}

The statistical analysis was performed using the SPSS 13.0. Dates are expressed as means \pm standard deviation $( \pm \mathrm{SD})$. Univariate-factor measurement data was analyzed by one-way analysis of variance (ANOVA). 
Repeated measurement data was analyzed by repeatedmeasures ANOVA. The interaction effects were analyzed by factorial ANOVA. Simple effects analyses were performed when an interaction was observed. Differences were considered statistically significant if $P$ value $<0.05$.

\section{Results}

\section{Physiological data of rats}

The $\mathrm{PaCO}_{2}$ levels were maintained at $35-45 \mathrm{mmHg}$ in the $\mathrm{S}$ and hypoxemia group, and hypercapnia treatment significantly increased the $\mathrm{PaCO}_{2}$ to $60-69 \mathrm{mmHg}$, with $\mathrm{pH}$ at 7.20-7.25 in the hypercapnia and $\mathrm{HH}$ group. Hypercapnia treatment had main effects on elevated $\mathrm{PaCO}_{2}$ levels (30 min: $\mathrm{df}=1, F=280.51, P<0.01 ; 60 \mathrm{~min}: \mathrm{df}=1$, $F=389.44, P<0.01 ; 120 \mathrm{~min}: \mathrm{df}=1, F=483.10, P<0.01$; 180 min: $\mathrm{df}=1, F=500.51, P<0.01)$ and reduced $\mathrm{pH}$ levels $(30 \mathrm{~min}: \mathrm{df}=1, F=260.18, P<0.01 ; 60 \mathrm{~min}$ : $\mathrm{df}=1$, $F=272.06, P<0.01 ; 120 \mathrm{~min}: \mathrm{df}=1, F=364.41, P<0.01$; 180 min: $\mathrm{df}=1, F=544.50, P<0.01$ ) (Fig. $1 \mathrm{a}-\mathrm{h}$ ). The $\mathrm{PO}_{2}$ levels were maintained at around $60 \mathrm{mmHg}$ in the hypoxemia and $\mathrm{HH}$ group. Hypoxia treatment had main effects on reduced $\mathrm{PaO}_{2}$ levels (30 min: $\mathrm{df}=1, F=157.52, P$ $<0.01 ; 60 \mathrm{~min}: \mathrm{df}=1, F=261.59, P<0.01 ; 120 \mathrm{~min}: \mathrm{df}=1$, $F=275.26, P<0.01 ; 180 \mathrm{~min}: \mathrm{df}=1, F=347.61, P<0.01)$ (Fig. 1i-l), while there were no interaction effects between hypercapnia treatment and hypoxia treatment $(P>0.05)$.

\section{Hypercapnia aggravated cognitive impairment in hypoxemic rats}

To elucidate the effect of hypercapnia on cognitive function in hypoxemic rats, we conducted MWM tests. There were significant interaction effects between hypercapnia treatment and hypoxia treatment ( $48 \mathrm{~h}: \mathrm{df}=1, F=4.12, P<0.05$; 72 h: $\mathrm{df}=1, F=6.56, P<0.05$ ) (Fig. $2 \mathrm{a}, \mathrm{b}$ ). In addition, simple effects analyses showed that there was no difference between hypercapnia group and $\mathrm{S}$ group $(48 \mathrm{~h}: \mathrm{df}=1, F=0.00$, $P>0.05 ; 72 \mathrm{~h}: \mathrm{df}=1, F=0.00, P>0.05)$. Hypoxemia group had a longer escape latency than $S$ group (48 h: $\mathrm{df}=1$, $F=10.15, P<0.01 ; 72 \mathrm{~h}: \mathrm{df}=1, F=10.44, P<0.01) . \mathrm{HH}$ group had the longest escape latency in comparison with hypercapnia group (48 h: $\mathrm{df}=1, F=36.69, P<0.01$; $72 \mathrm{~h}: \mathrm{df}=1, F=46.98, P<0.01$ ) and hypoxemia group (48 h: $\mathrm{df}=1, F=8.62, P<0.01 ; 72 \mathrm{h:} \mathrm{df}=1, F=13.09, P<0.01)$ (Fig. 2 c).

\section{Hypercapnia enhanced activation of NLRP3 inflammasome and expression of IL-1 $\beta$ in the hypoxic hippocampus}

To explore the effects of hypercapnia on the expression of IL-1 $\beta$ and activation of NLRP3 inflammasome, the protein expression of IL-1 $\beta$ and members of NLRP3 inflammasome including NLRP3, pro-caspase-1, and caspase- 1 in the hippocampus was detected by Western blot analysis. There were significant interaction effects between hypercapnia treatment and hypoxia treatment (NLRP3: $\mathrm{df}=1, F=11.54, P<0.01$; pro-caspase-1: $\mathrm{df}=1$, $F=21.55, P<0.01$; caspase $-1: \mathrm{df}=1, F=6.02, P<0.05$; IL-1 $\beta: \mathrm{df}=1, F=12.57, P<0.01$ ) (Figs. $3 \mathrm{c}-\mathrm{e}$ and $4 \mathrm{~b}$ ). In addition, simple effects analyses showed that the protein expression levels in hypercapnia group had no significant difference compared with $\mathrm{S}$ group (NLRP3: $\mathrm{df}=1$, $F=0.01, P>0.05$; pro-caspase- $1: \mathrm{df}=1, F=0.06, P>0.05$; caspase-1: $\mathrm{df}=1, i=0.16, P>0.05 ; \mathrm{IL}-1 \beta: \mathrm{df}=1, F=0.00$, $P>0.05)$. The protein expression levels in hypoxemia group were significantly increased compared with $\mathrm{S}$ group (NLRP3: $\mathrm{df}=1, F=102.57, P<0.01$; pro-caspase1: $\mathrm{df}=1, F=72.76, P<0.01$; caspase- $1: \mathrm{df}=1, F=51.48$, $P<0.01$; IL-1 $\beta$ : df $=1, F=26.50, P<0.01)$. HH group had the highest levels of the protein in comparison with hypercapnia group (NLRP3: $\mathrm{df}=1, F=222.94, P<0.01$; pro-caspase-1: $\mathrm{df}=1, \mathrm{~F}=227.86, P<0.01$; caspase- 1 : $\mathrm{df}=1$, $F=117.93, P<0.01$; IL-1 $\beta: \mathrm{df}=1, F=103.25, P<0.01)$ and Hypoxemia group (NLRP3: $\mathrm{df}=1, F=23.81, P<0.01$; pro-caspase-1: $\mathrm{df}=1, F=40.04, P<0.01$; caspase-1: $\mathrm{df}=1$, $F=10.77, P<0.01$; IL-1 $\beta: \mathrm{df}=1, \mathrm{~F}=25.62, P<0.01$ ) (Figs. $3 \mathrm{a}, \mathrm{b}$ and $4 \mathrm{a}, \mathrm{c})$.

\section{Hypercapnia increased the expression of IL-1 $\beta$ in activated microglia in the hypoxic hippocampus}

To investigate whether hypercapnia would increase the expression of IL-1 $\beta$ in microglia, IL- $1 \beta$ in the microglia in hippocampus CA1 area was examined by double immunofluorescence. Hypercapnia alone is not enough to cause immunofluorescence enhancement of IL-1 $\beta$. The immunofluorescence of IL-1 $\beta$ in hypoxia-activated microglia in the hippocampus was noticeably enhanced. Additionally, the immunofluorescence was further enhanced following treatment of hypercapnia in the hypoxic hippocampus (Fig. 4d). The average fluorescence density of one single microglia in hypoxemia group and $\mathrm{HH}$ group was analyzed by an image analysis system (Image-Pro Plus software). The fluorescence density in $\mathrm{HH}$ group was significantly increased compared with hypoxemia group $(P<0.01)$ (Fig. $4 \mathrm{e})$.

\section{Hypercapnia aggravated apoptosis of hippocampal neurons of hypoxemic rats}

To determine if hypercapnia played any role in apoptosis of hippocampal neurons in hypoxemic rats, the expression levels of Bcl-2, Bax, and caspase-3 were examined by Western blot analysis. There were significant interaction effects between hypercapnia treatment and hypoxia treatment (Bcl-2: $\mathrm{df}=1, F=9.73, P<0.01$; Bax: $\mathrm{df}=1, F=6.26$, $P<0.05$; caspase-3: $\mathrm{df}=1, F=7.74, P<0.05$ ) (Figs. $5 \mathrm{~b}, \mathrm{c}$ and $6 \mathrm{~b})$. In addition, simple effects analyses showed that the protein expression of Bcl-2, Bax, and caspase- 3 in hypercapnia group had no significant difference compared with $\mathrm{S}$ group (Bcl-2: $\mathrm{df}=1, F=0.00, P>0.05$; Bax: $\mathrm{df}=1$, 


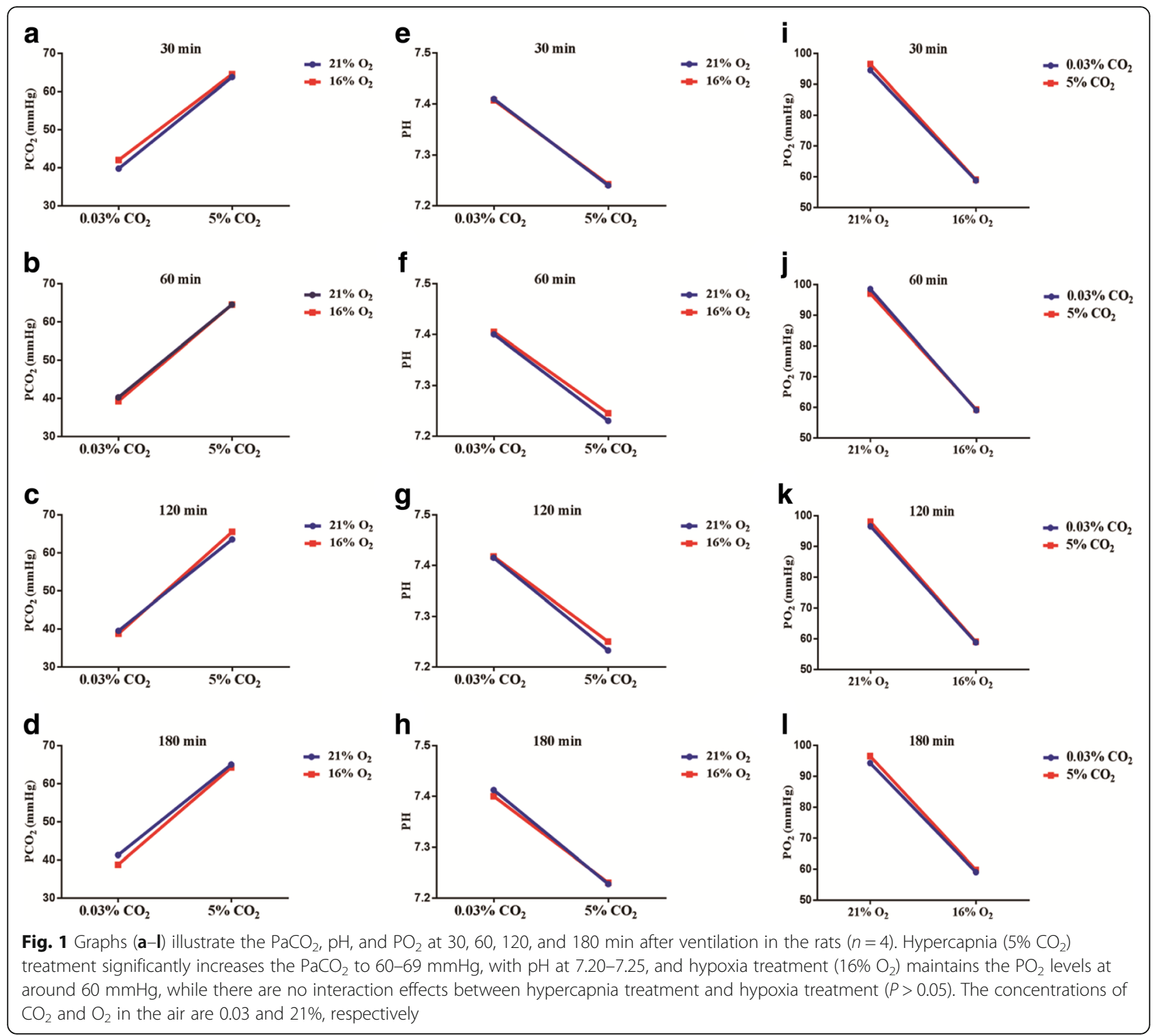

$F=0.05, P>0.05$; caspase- $3: \mathrm{df}=1, F=0.01, P>0.05)$. The protein expression levels of $\mathrm{Bcl}-2$ in hypoxemia group were significantly decreased compared with $\mathrm{S}$ group $(\mathrm{df}=1$, $F=43.77, P<0.01)$. HH group had the lowest levels of the protein in comparison with hypercapnia group $(\mathrm{df}=1, F=$ 121.59, $P<0.01)$ and hypoxemia group $(\mathrm{df}=1, F=19.45$, $P<0.01)$. In contrast, a significant increase in Bax and caspase-3 expression was observed in hypoxemia group compared with $\mathrm{S}$ group (Bax: $\mathrm{df}=1, F=39.67, P<0.01$; caspase-3: $\mathrm{df}=1, F=26.24, P<0.01)$. The levels of Bax and caspase-3 expression in $\mathrm{HH}$ group were the highest as compared to hypercapnia group (Bax: $\mathrm{df}=1, F=96.77, P<0.01$; caspase-3: $\mathrm{df}=1, F=82.02, P<0.01)$ and hypoxemia group (Bax: $\mathrm{df}=1, F=11.06, P<0.01$; caspase- 3 : $\mathrm{df}=1, F=14.76$, $P<0.01$ ) (Figs. 5a, d and 6a, c).
To investigate whether hypercapnia would aggravate apoptosis of hippocampal neurons, expression of caspase3 in the neurons in hippocampus CA1 area was examined by double immunofluorescence. Hypercapnia alone was not enough to cause immunofluorescence enhancement of caspase-3. The immunofluorescence in neurons in the hypoxic hippocampus was noticeably enhanced. Additionally, the immunofluorescence was further augmented following hypercapnia in the hypoxic hippocampus (Fig. 6d).

\section{$\mathrm{PO}_{2}, \mathrm{PCO}_{2}$, and $\mathrm{pH}$ of supernatants}

The $\mathrm{PaCO}_{2}$ levels were maintained at $35-45 \mathrm{mmHg}$ in the control and hypoxia group, and $15 \% \mathrm{CO}_{2}$ treatment significantly increased the $\mathrm{PaCO}_{2}$, with $\mathrm{pH}$ at 7.20-7.25 in the $\mathrm{HC}$ and hypoxia $+\mathrm{HC}$ group. $15 \% \mathrm{CO}_{2}$ treatment 


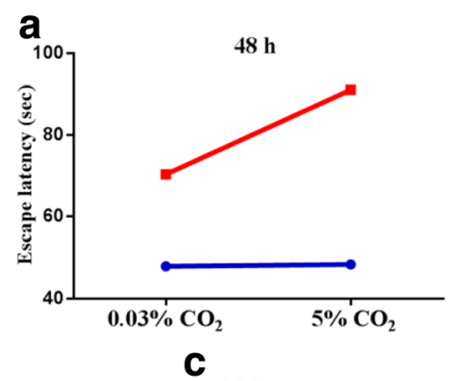

C

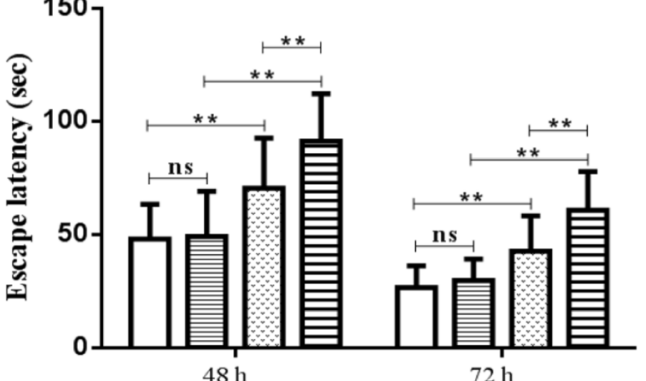

$-21 \% \mathrm{O}_{2}$
$-16 \% \mathrm{O}_{2}$

$72 \mathrm{~h}$
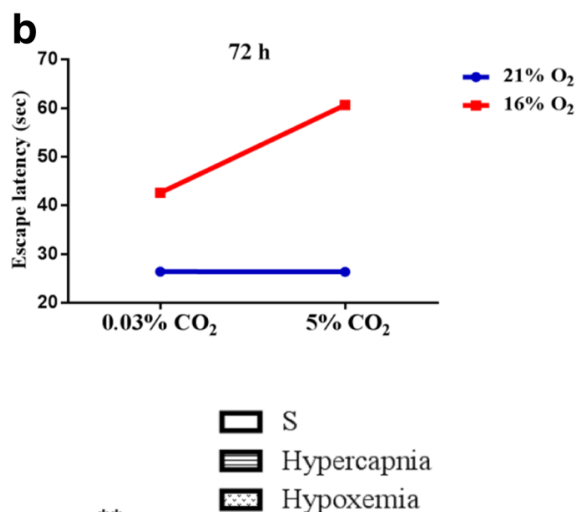

Е $\mathrm{HH}$

Fig. 2 Average MWM latency time of rats in all groups $(n=15)$. $\mathbf{a}, \mathbf{b}$ There are significant interaction effects between hypercapnia and hypoxia treatment at 48 and $72 \mathrm{~h}(P<0.05)$. c Simple effects analyses show that there is no difference between hypercapnia group and $\mathrm{S}$ group at 48 and $72 \mathrm{~h}$ (ns $P>0.05)$. Hypoxemia group has a longer escape latency than $\mathrm{S}$ group at 48 and $72 \mathrm{~h}(* * P<0.01)$. HH group has the longest escape latency in comparison with hypercapnia group ( $\left.{ }^{* * P}<0.01\right)$ and hypoxemia group $\left.{ }^{*} P<0.01\right)$ at 48 and $72 \mathrm{~h}$. $S$ group sham-operated group, $H H$ group hypercapnia + hypoxemia group. The concentrations of $\mathrm{CO}_{2}$ and $\mathrm{O}_{2}$ in the air are 0.03 and $21 \%$, respectively

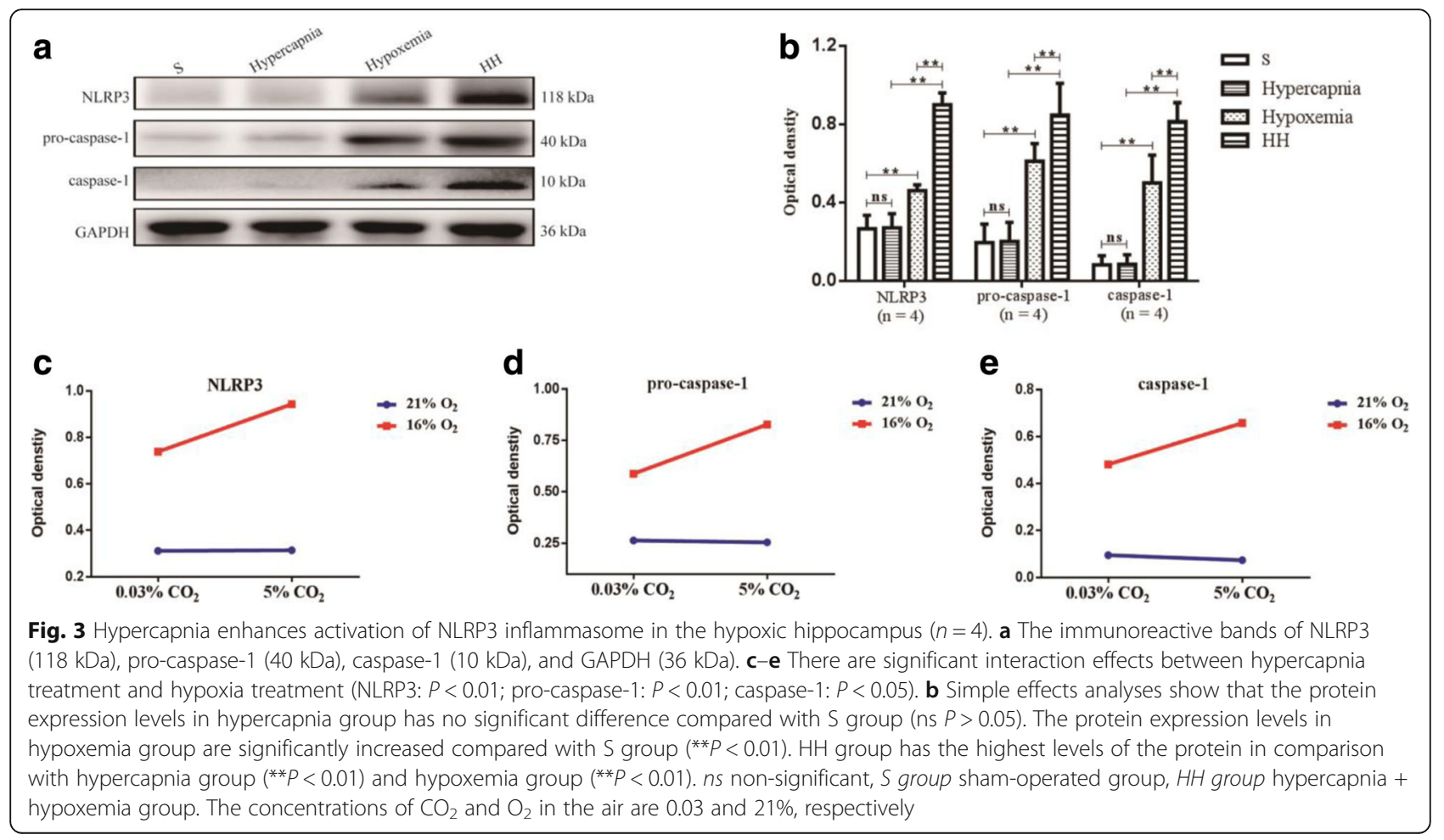



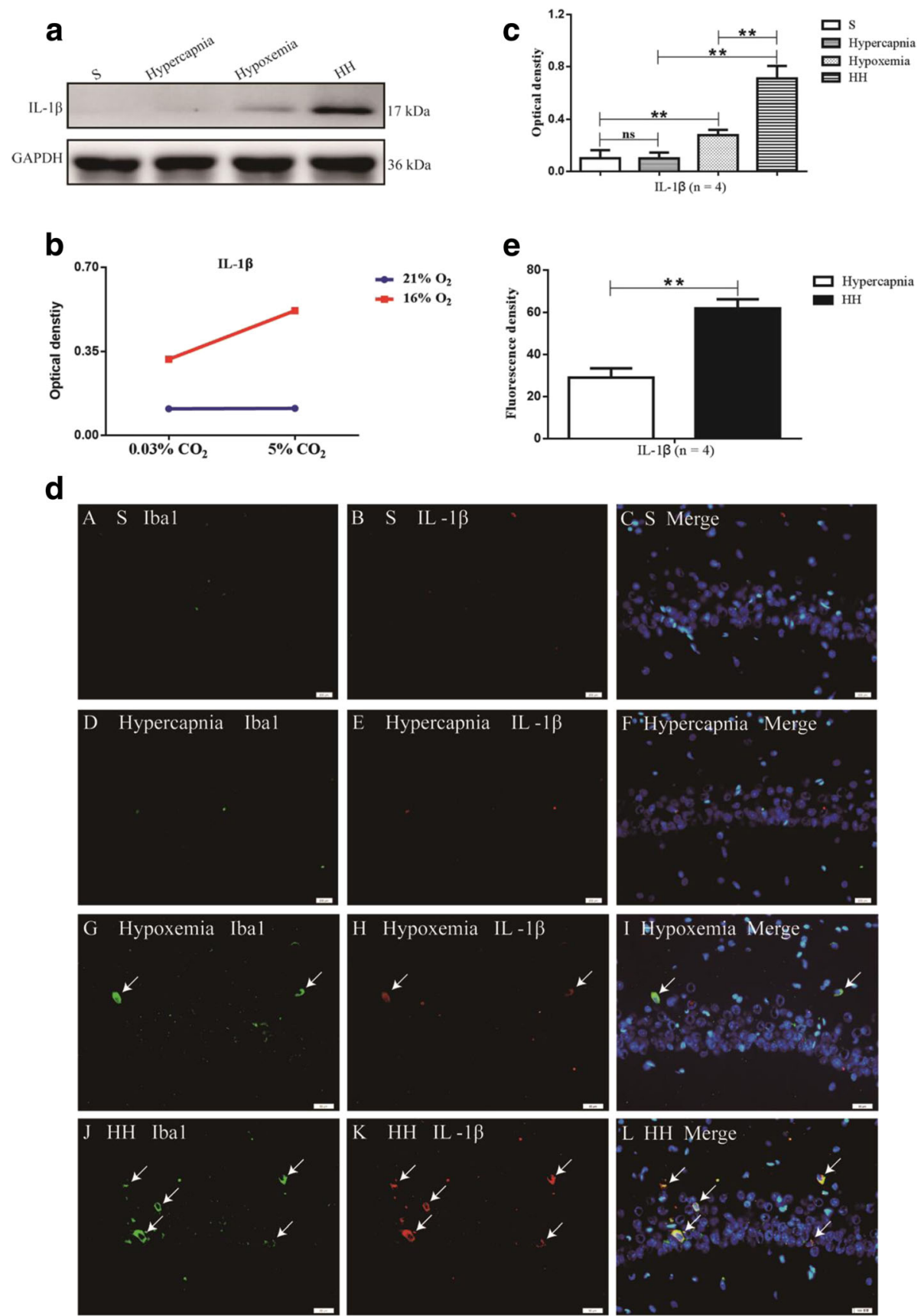

Fig. 4 Hypercapnia enhances the release of IL-1 $\beta$ in the hypoxic hippocampus $(n=4)$. a The immunoreactive bands of IL-1 $(17 \mathrm{kDa})$ and GAPDH (36 kDa). b There is a significant interaction effect between hypercapnia treatment and hypoxia treatment $(P<0.01)$. c Simple effects analyses show that the protein expression levels of IL-1 $\beta$ in hypercapnia group have no significant difference compared with $S$ group (ns $P>0.05$ ). The protein expression levels in hypoxemia group are significantly increased compared with $S$ group $\left({ }^{* *} P<0.01\right)$. HH group has the highest levels of the protein in comparison with hypercapnia group (**P< 0.01) and hypoxemia group (**P<0.01). d Immunofluorescence images show the expression of IL-1 $\beta\left(B, E, H, K\right.$, red), Iba $1^{+}$microglia $(A$, $D, G, J$, green), and the co-localization of $I L-1 \beta$ and microglia $(C, F, I, L)$. The results also show that hypercapnia alone is not enough to increase the expression of $I L-1 \beta$. The expression of IL-1 $\beta$ in activated microglia in the hypoxic hippocampus is markedly increased. Additionally, the expression of $I L-1 \beta$ is further enhanced following treatment of hypercapnia in the hypoxic hippocampus. Scale bars: (A-L), $20 \mu \mathrm{m}$. e The average fluorescence (red) density of one single microglia in hypoxemia group and HH group was analyzed by an image analysis system (Image-Pro Plus software). Statistical significance was examined by $t$ test. The fluorescence density in $\mathrm{HH}$ group is significantly increased compared with hypoxemia group $(* * P<0.01)$. ns non-significant, $L L-1 \beta$ interleukin- 1 beta, $S$ group sham-operated group, $\mathrm{HH}$ group hypercapnia + hypoxemia group. The concentrations of $\mathrm{CO}_{2}$ and $\mathrm{O}_{2}$ in the air are 0.03 and $21 \%$, respectively 

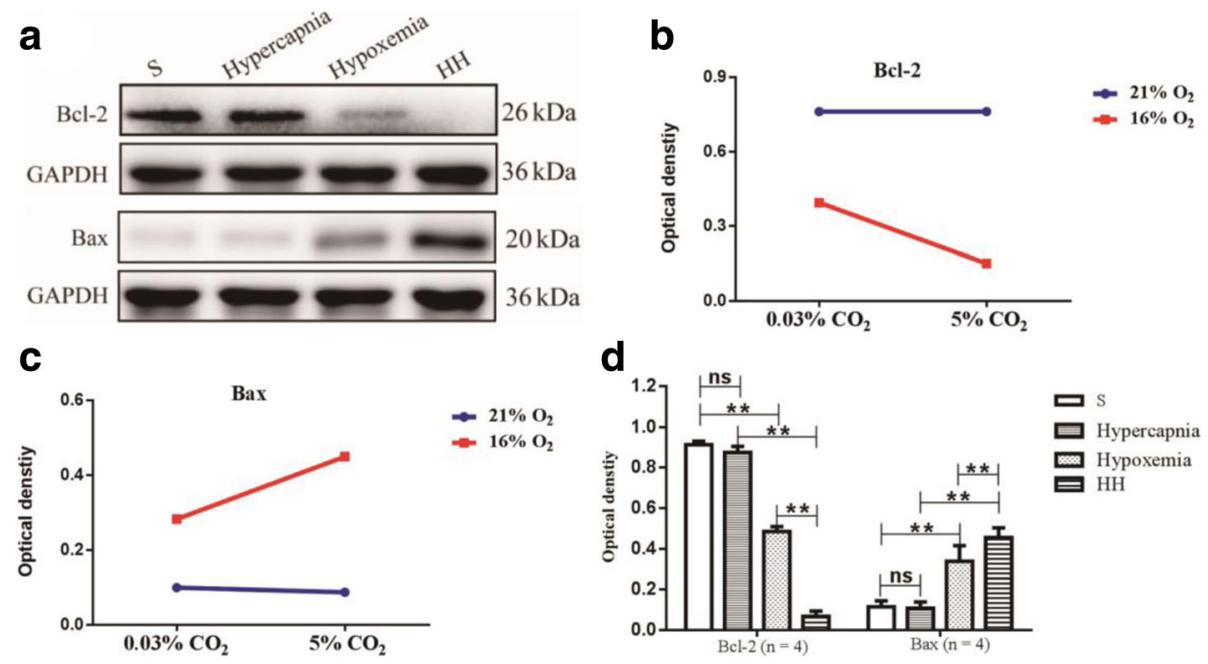

Fig. 5 Hypercapnia aggravates apoptosis of hippocampal neurons of hypoxemic rats $(n=4)$. a The immunoreactive bands of $B c l-2(26 \mathrm{kDa})$, Bax $(20 \mathrm{kDa})$, and GAPDH $(36 \mathrm{kDa})$. b, c There are significant interaction effects between hypercapnia treatment and hypoxia treatment $(\mathrm{Bcl}-2: P<0.01 ;$ Bax: $P<0.05)$. $\mathbf{d}$ Simple effects analyses show that the protein expression levels of $\mathrm{BCl}-2$ and $\mathrm{Bax}$ in hypercapnia group have no significant difference compared with $S$ group (ns $P>0.05$ ). The protein expression levels of $\mathrm{BCl}-2$ in hypoxemia group are significantly decreased compared with $\mathrm{S}$ group ( $\left.{ }^{* *} P<0.01\right)$. HH group has the lowest levels of the protein in comparison with hypercapnia group $(* * P<0.01)$ and hypoxemia group $\left.{ }^{* *} P<0.01\right)$. In contrast, a significant increase in Bax expression is observed in hypoxemia group compared with $\mathrm{S}$ group $(* * P<0.01)$. The levels of Bax expression in $\mathrm{HH}$ group is the highest as compared to hypercapnia group ( $\left.{ }^{* *} P<0.01\right)$ and hypoxemia group $\left({ }^{* *} P<0.01\right)$. S group sham-operated group, $H H$ group hypercapnia + hypoxemia group. The concentrations of $\mathrm{CO}_{2}$ and $\mathrm{O}_{2}$ in the air are 0.03 and $21 \%$, respectively

had main effects on elevated $\mathrm{PaCO}_{2}$ levels $(6 \mathrm{~h}: \mathrm{df}=1$, $F=2966.47, P<0.01 ; 12$ h: $\mathrm{df}=1, F=3469.17, P<0.01$; $24 \mathrm{~h}: \mathrm{df}=1, F=3594.06, P<0.01)$ and reduced $\mathrm{pH}$ levels $(6 \mathrm{~h}: \mathrm{df}=1, F=2035.57, P<0.01 ; 12 \mathrm{~h}: \mathrm{df}=1$, $F=3207.76, P<0.01 ; 24 \mathrm{~h}: \mathrm{df}=1, F=3483.16, P<0.01$ ) (Fig. $7 \mathrm{a}-\mathrm{f}$ ). The $\mathrm{PaO}_{2}$ values were maintained at around $60 \mathrm{mmHg}$ in the hypoxia and hypoxia + $\mathrm{HC}$ group. $0.2 \%$ $\mathrm{O}_{2}$ treatment had main effects on reduced $\mathrm{PaO}_{2}$ levels (6 h: $\mathrm{df}=1, F=8342.41, P<0.01 ; 12 \mathrm{~h}: \mathrm{df}=1, F=10,597.52$, $P<0.01 ; 24 \mathrm{~h}: \mathrm{df}=1, F=14,040.21, P<0.01$ ) (Fig. $7 \mathrm{~g}-\mathrm{i}$ ), while there were no interaction effects between $15 \% \mathrm{CO}_{2}$ treatment and $0.2 \% \mathrm{O}_{2}$ treatment $(P>0.05)$.

Higher levels of $\mathrm{CO}_{2}$ treatment time-dependently increased protein expression of IL-1 $\beta$ in hypoxic BV-2 cells

To determine the optimal time-point of intervention for the cells, the protein expression of IL- $1 \beta$ in the BV-2 cells was examined by Western blot at 6,12 , and $24 \mathrm{~h} .15 \% \mathrm{CO}_{2}$ treatment increased the protein expression of IL- $1 \beta$ in hypoxic BV-2 cells with the prolonging of time; there was significant difference among each group $(\mathrm{df}=3, F=42.22, P<0.01)$. In view of this, the time-point $24 \mathrm{~h}$ was chosen as the intervention time in the follow-up in vitro experiment (Fig. 8a, b).

High concentration of $\mathrm{CO}_{2}$ enhanced activation of NLRP3 inflammasome coupled with increased IL-1 $\beta$ expression in hypoxic BV-2 microglia

To explore the effects of high concentration of $\mathrm{CO}_{2}$ on activation of NLRP3 inflammasome and the expression of IL-1 $\beta$, the protein expression of IL-1 $\beta$, NLRP3, procaspase-1, and caspase-1 in BV-2 microglia was detected by Western blot. There were significant interaction effects between $15 \% \quad \mathrm{CO}_{2}$ treatment and $0.2 \% \quad \mathrm{O}_{2}$ treatment (NLRP3: $\mathrm{df}=1, F=11.25, P<0.01$; pro-caspase-1: $\mathrm{df}=1, F$ $=10.60, P<0.01$; caspase- $1: \mathrm{df}=1, F=7.47, P<0.05$; IL-1 $\beta$ : $\mathrm{df}=1, F=6.24, P<0.05$ ) (Figs. $9 \mathrm{c}-\mathrm{e}$ and $10 \mathrm{~b}$ ). In addition, simple effects analyses showed that the protein expression in HC group had no significant difference compared with control group (NLRP3: $\mathrm{df}=1, F=0.14, P>0.05$; procaspase-1: $\mathrm{df}=1, F=0.03, P>0.05$; caspase $-1: \mathrm{df}=1$, $F=0.03, P>0.05 ; \mathrm{IL}-1 \beta: \mathrm{df}=1, F=0.06, P>0.05)$. The protein expression levels in hypoxia group were significantly increased compared with control group (NLRP3: $\mathrm{df}=1, F=47.14, P<0.01$; pro-caspase-1: $\mathrm{df}=1$, $F=56.88, P<0.01$; caspase- $1: \mathrm{df}=1, F=37.92, P<0.01$; IL-1 $\beta: \mathrm{df}=1, F=31.91, P<0.01)$. Hypoxia + HC group had the highest levels of the protein in comparison with HC group (NLRP3: $\mathrm{df}=1, F=134.79, P<0.01$; pro-caspase-1: $\mathrm{df}=1, F=212.38, P<0.01$; caspase-1: $\mathrm{df}=1, F$ $=100.46, \quad P<0.01 ; \quad$ IL-1 $\beta: \quad \mathrm{df}=1, \quad F=84.31, \quad P<0.01)$ and hypoxia group (NLRP3: $\mathrm{df}=1, F=26.20, P<0.01$; pro-caspase-1: $\mathrm{df}=1, F=51.86, P<0.01$; caspase- $1: \mathrm{df}=1$, $F=16.36, P<0.01 ; \mathrm{IL}-1 \beta: \mathrm{df}=1, F=14.33, P<0.01)$. The protein expression of IL-1 $\beta$ was markedly enhanced by high concentration of $\mathrm{CO}_{2}$ in hypoxic BV-2 microglia; it was significantly suppressed with the treatment of $10 \mu \mathrm{M}$ Z-YVAD-FMK $(P<0.01)$ (Figs. 9a, b and 10a, c). 

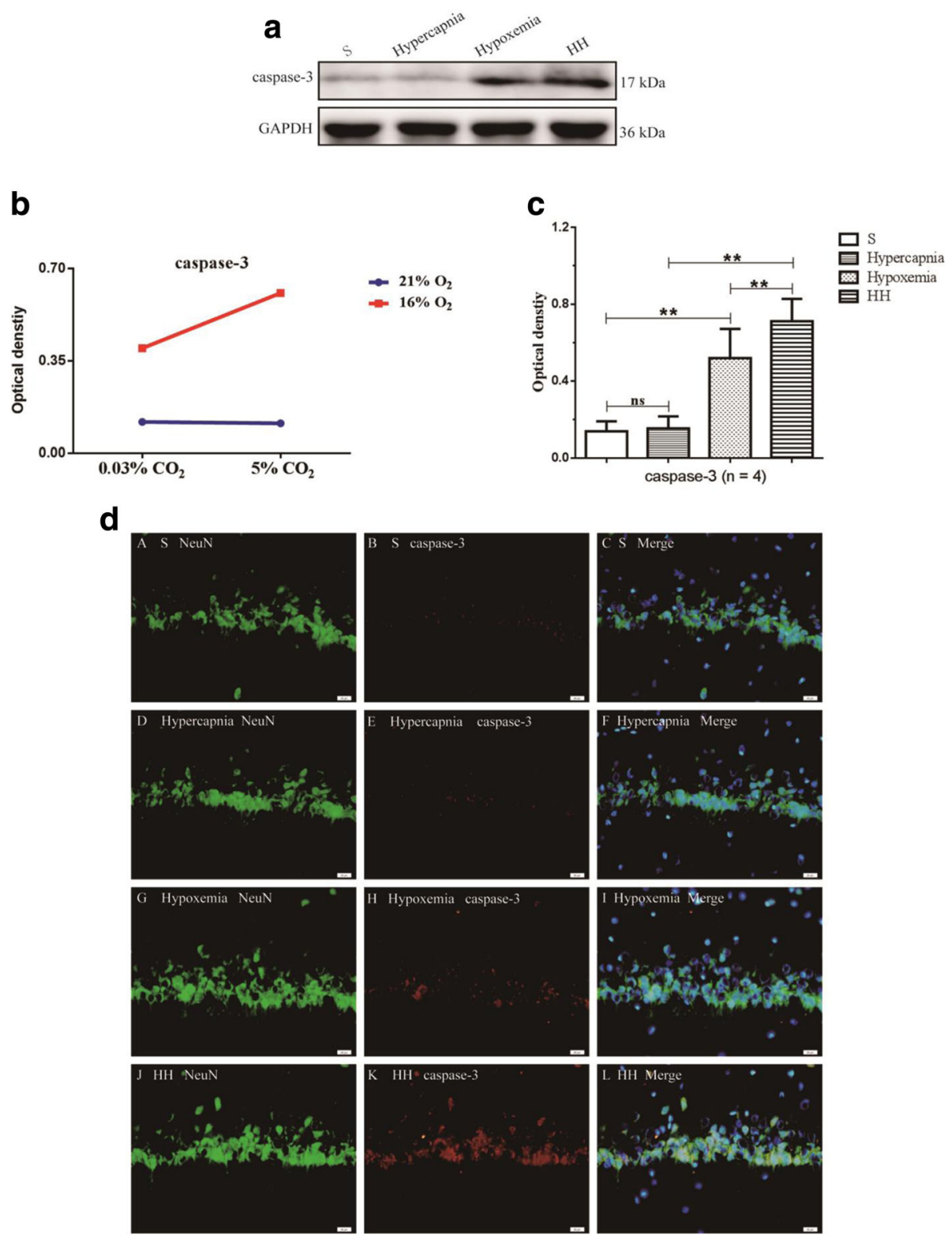

Fig. 6 Hypercapnia aggravates apoptosis of hippocampal neurons of hypoxemic rats $(n=4)$. a The immunoreactive bands of caspase-3 $(17 \mathrm{kDa})$ and GAPDH (36 kDa). b There is a significant interaction effect between hypercapnia treatment and hypoxia treatment $(P<0.05)$. c Simple effects analyses show that the protein expression levels of caspase- 3 in hypercapnia group have no significant difference compared with $S$ group (ns $P>0.05$ ). A significant increase in caspase-3 expression is observed in hypoxemia group compared with $\mathrm{S}$ group $\left({ }^{* *} P<0.01\right)$. The levels of caspase-3 expression in $\mathrm{HH}$ group is the highest as compared to hypercapnia group $\left.{ }^{* *} P<0.01\right)$ and hypoxemia group ( $\left.{ }^{* *} P<0.01\right)$. d Immunofluorescence images show the expression of caspase-3 $(B, E, H, K$, red), NeuN ${ }^{+}$neurons (A, D, G, J, green), and the co-localization of caspase-3 and neurons $(C, F, I, L)$. The results also show that hypercapnia alone is not enough to increase the expression of caspase-3. The expression of caspase-3 in neurons in the hypoxic hippocampus is markedly increased. Additionally, the expression of caspase-3 is further enhanced following treatment of hypercapnia in the hypoxic hippocampus. Scale bars: (A-L), 20 um. $S$ group shamoperated group, $\mathrm{HH}$ group hypercapnia + hypoxemia group. The concentrations of $\mathrm{CO}_{2}$ and $\mathrm{O}_{2}$ in the air are 0.03 and $21 \%$, respectively

High concentration of $\mathrm{CO}_{2}$ is not enough to cause immunofluorescence enhancement of NLRP3, caspase1 , and IL-1 $\beta$ in BV-2 microglia without hypoxia. However, the immunofluorescence in hypoxiaactivated BV-2 microglia was noticeably enhanced. Additionally, the immunofluorescence was further enhanced following treatment of high concentration of $\mathrm{CO}_{2}$ in hypoxia-activated BV-2 microglia (Figs. 9f and $10 \mathrm{~d})$.

High concentration of $\mathrm{CO}_{2}$ aggravated apoptosis of cultured neurons via hypoxia-activated microglia

To determine if high concentration of $\mathrm{CO}_{2}$ played any role in apoptosis of cultured neurons via hypoxia-activated 


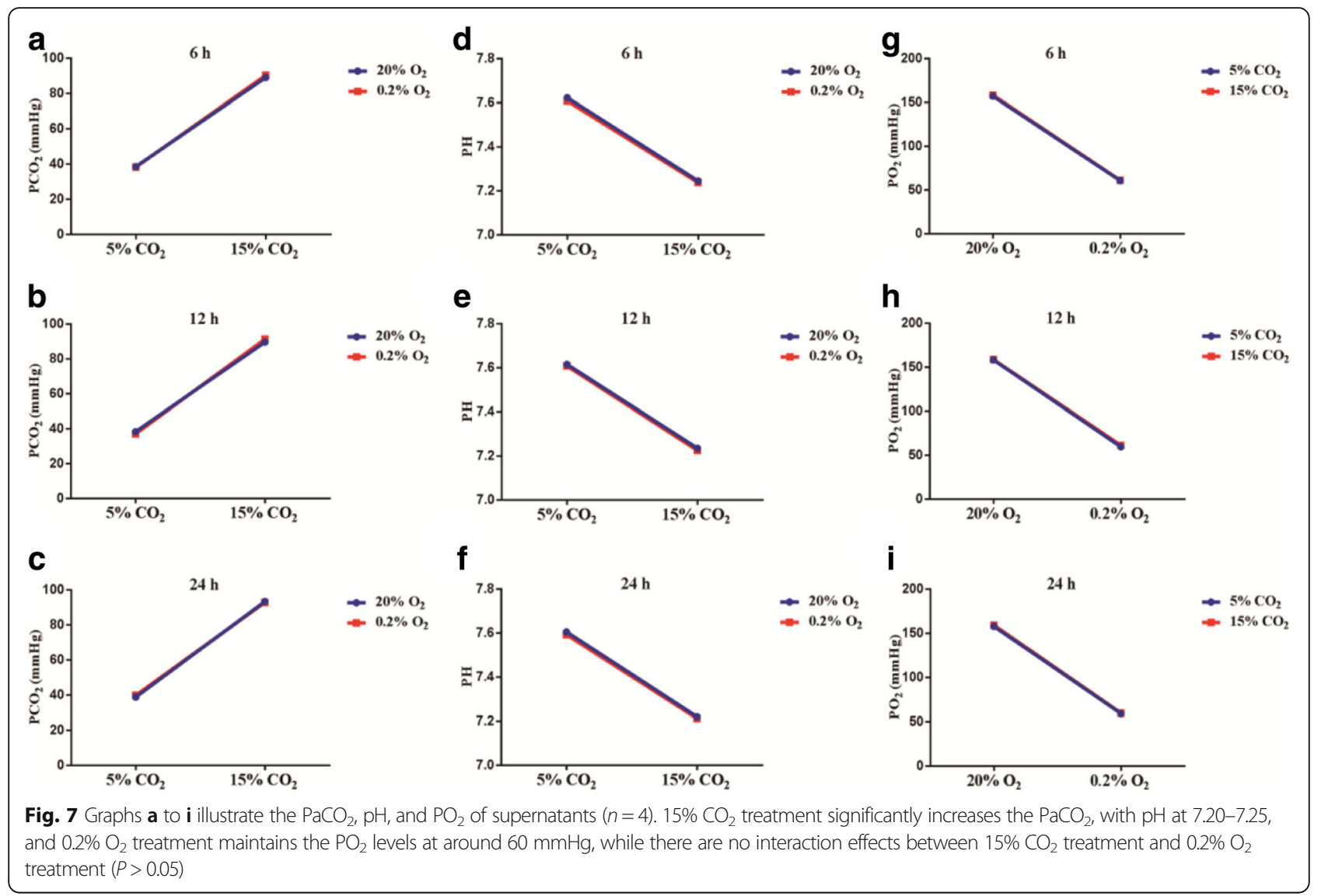

microglia, cultured microglia cells were stimulated with $0.2 \% \mathrm{O}_{2}$ or (and) $15 \% \mathrm{CO}_{2}$, and conditioned medium derived from those cultures was used to maintain neuronal cultures. The expression levels of Bcl-2, Bax, and caspase-3 of neurons were examined by Western blot analysis. There were significant interaction effects between $\mathrm{CM}+\mathrm{HC}$ treatment and $\mathrm{CM}+$ hypoxia treatment $(\mathrm{Bcl}-2: \mathrm{df}=1$, $F=5.89, P<0.05$; Bax: $\mathrm{df}=1, F=8.02, P<0.05$; caspase-3: $\mathrm{df}=1, F=7.68, P<0.05$ ) (Figs. 11c-e). In addition, simple effects analyses showed that the protein expression of Bcl-2, Bax, and caspase- 3 in $\mathrm{CM}+\mathrm{HC}$ group had no significant difference compared with $\mathrm{CM}$ group $(\mathrm{Bcl}-2$ : $\mathrm{df}=1, F=0.51$,
$P>0.05$; Bax: $\mathrm{df}=1, F=0.02, P>0.05$; caspase $-3: \mathrm{df}=1$, $F=0.02, P>0.05)$. The protein expression levels of Bcl-2 in $\mathrm{CM}+$ hypoxia group were significantly decreased compared with $\mathrm{CM}$ group $(\mathrm{df}=1, F=70.86, P<0.01)$. $\mathrm{CM}+$ hypoxia $+\mathrm{HC}$ group had the lowest levels of the protein in comparison with $\mathrm{CM}+\mathrm{HC}$ group $(\mathrm{df}=1, F=140.42$, $P<0.01)$ and $\mathrm{CM}+$ hypoxia group $(\mathrm{df}=1, F=17.17$, $P<0.01)$. In contrast, a significant increase in Bax and caspase-3 expression was observed in $\mathrm{CM}+$ hypoxia group compared with $\mathrm{CM}$ group (Bax: $\mathrm{df}=1, F=72.16, P<0.01$; caspase-3: $\mathrm{df}=1, F=112.55, P<0.01)$. The levels of Bax and caspase- 3 expression in $\mathrm{CM}+$ hypoxia $+\mathrm{HC}$ group
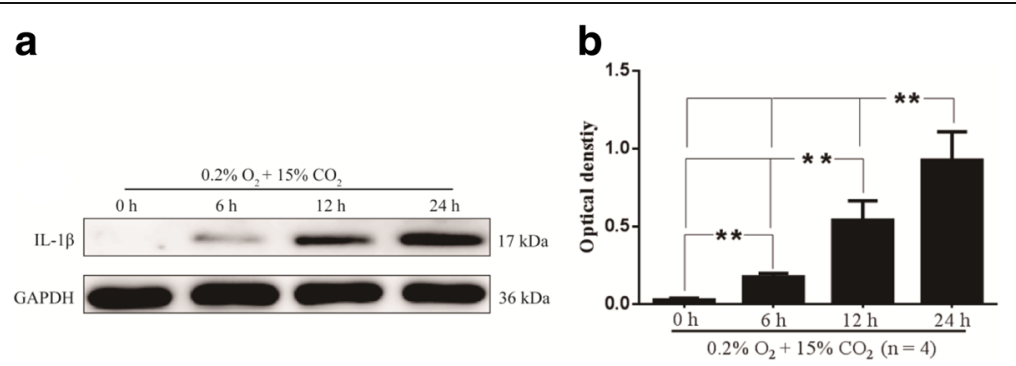

Fig. 8 Higher levels of $\mathrm{CO}_{2}$ treatment time-dependently increase protein expression of IL-1 $\beta$ in hypoxic BV-2 cells $(n=4)$. a The immunoreactive bands of IL-1 1 (17 kDa) and GAPDH (36 kDa). Bar graph $\mathbf{b}$ shows the protein expression of IL-1 $\beta$ in hypoxic BV-2 cells is increased with the prolonging of time, and there is significant difference among each group $\left({ }^{*} P<0.01\right)$. IL-1 $\beta$ interleukin- 1 beta 

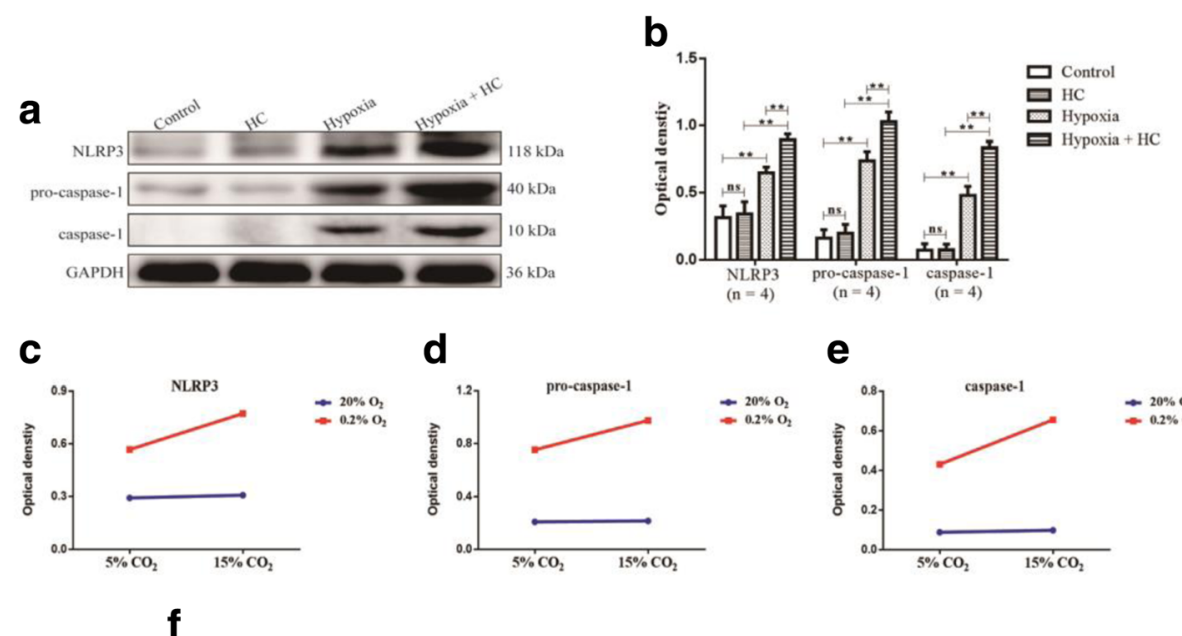

d e

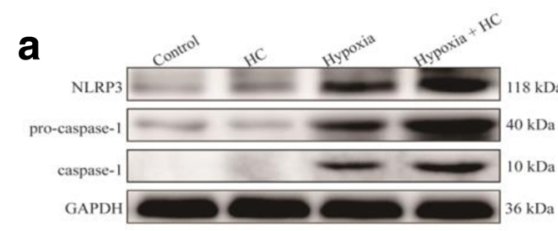

e
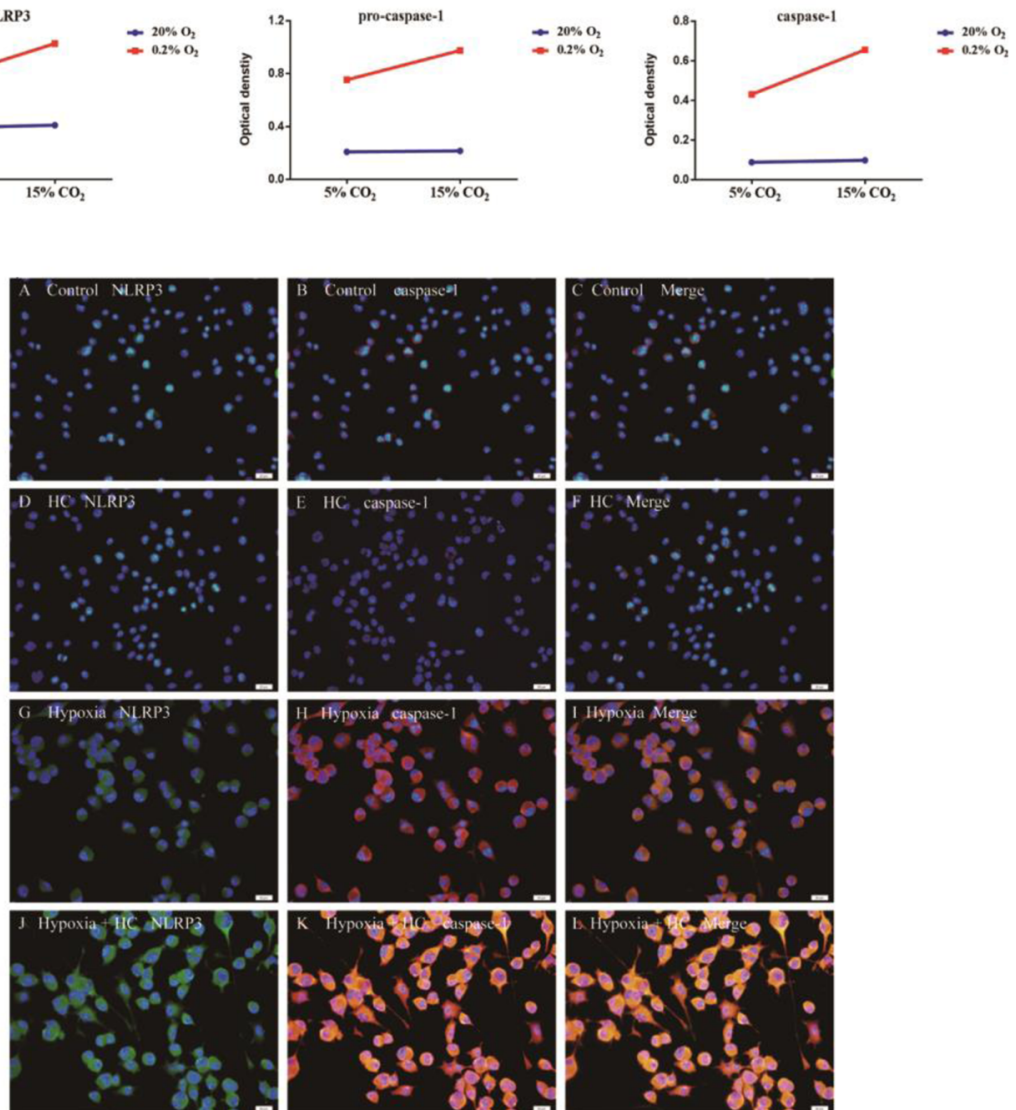

Fig. 9 High concentration of $\mathrm{CO}_{2}$ enhances activation of NLRP3 inflammasome in hypoxic BV-2 microglia $(n=4)$. a The immunoreactive bands of NLRP3 $(118 \mathrm{kDa})$, pro-caspase-1 (40 kDa), caspase-1 (10 kDa), and GAPDH (36 kDa). c-e There are significant interaction effects between $15 \% \mathrm{CO}_{2}$ treatment and $0.2 \% \mathrm{O}_{2}$ treatment (NLRP3: $P<0.01$; pro-caspase-1: $P<0.01$; caspase-1: $P<0.05$ ). $\mathbf{b}$ Simple effects analyses show that the protein expression in $\mathrm{HC}$ group has no significant difference compared with control group (ns $P>0.05$ ). The protein expression levels in hypoxia group are significantly increased compared with control group (**P<0.01). Hypoxia $+\mathrm{HC}$ group has the highest levels of the protein in comparison with $\mathrm{HC}$ group $(* * P<0.01)$ and hypoxia group $\left.{ }^{* *} P<0.01\right)$. $\mathbf{I}$ Immunofluorescence images show the expression of caspase-1 (B, E, H, K, red), NLRP3 ( $A, D, G$, J, green), and the co-localization of caspase-1 and NLRP3 $(C, F, I, L)$. The results also show that high concentration of $\mathrm{CO}_{2}\left(15 \% \mathrm{CO}_{2}\right)$ alone is not enough to increase the expression of caspase-1 and NLRP3. The expression of caspase-1 and NLRP3 in hypoxia-activated BV-2 microglia is markedly increased. Additionally, the expression of caspase-1 and NLRP3 is further enhanced following treatment of $15 \% \mathrm{CO}_{2}$ in the hypoxic BV-2 microglia. Scale bars: (A-L), $20 \mu \mathrm{m}$. HC group high concentration of carbon dioxide group

were the highest as compared to $\mathrm{CM}+\mathrm{HC}$ group (Bax: $\mathrm{df}=1, F=156.25, P<0.01$; caspase-3: $\mathrm{df}=1, F=$ 211.07, $P<0.01$ ) and $\mathrm{CM}+$ hypoxia group (Bax: $\mathrm{df}=1, F=$ 17.17, $P<0.01$; caspase-3: $\mathrm{df}=1, F=16.44, P<0.01)$. When BV-2 conditioned medium was pretreated with Z-YVADFMK, the protein expression of caspase- 3 of neurons was significantly suppressed $(P<0.01)$ (Figs. 11a-f).

\section{Discussion}

In the present study, we have found that hypercapnia alone is not sufficient to induce cognitive impairment, but hypercapnia can significantly aggravate the cognitive function of hypoxic rats. In the MWM test, rats treated with hypercapnia + hypoxia had significantly longer escape latency than those treated with hypoxia. Additionally, 

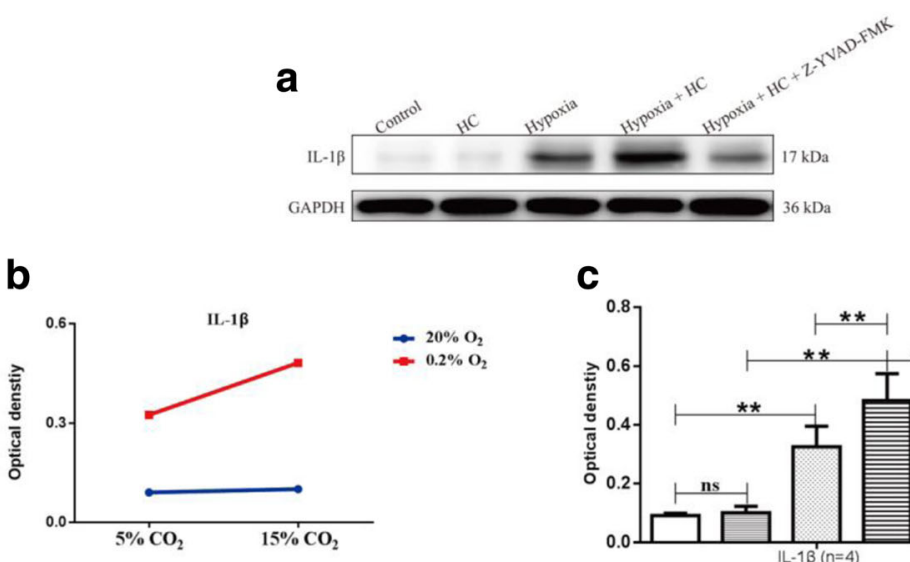

C

d
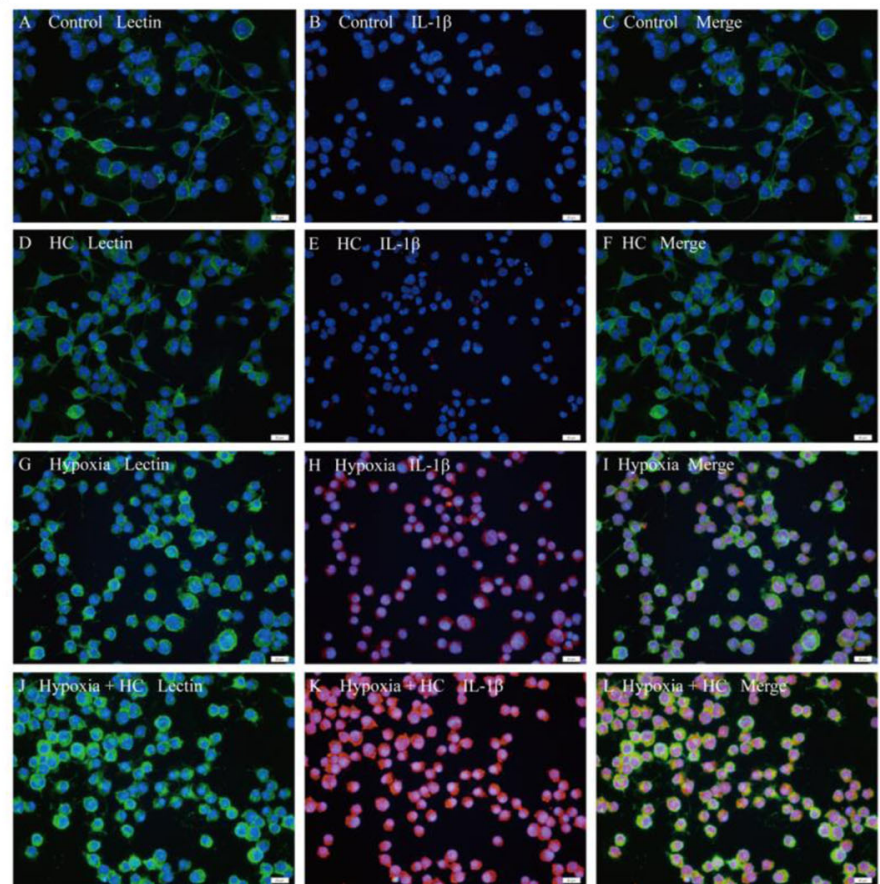

Fig. 10 High concentration of $\mathrm{CO}_{2}$ enhances the expression of IL-1 $\beta$ in hypoxic BV-2 microglia $(n=4)$. a The immunoreactive bands of IL-1 $\beta$ $(17 \mathrm{kDa})$ and GAPDH $(36 \mathrm{kDa})$. b There is a significant interaction effect between $15 \% \mathrm{CO}_{2}$ treatment and $0.2 \% \mathrm{O}_{2}$ treatment $(P<0.05)$. c Simple effects analyses show that the protein expression of IL-1 $\beta$ in $\mathrm{HC}$ group has no significant difference compared with Control group (ns $P>0.05$ ). The protein expression levels in hypoxia group are significantly increased compared with control group (** $P<0.01$ ). Hypoxia $+\mathrm{HC}$ group had the highest levels of the protein in comparison with $\mathrm{HC}$ group $(* * P<0.01)$ and hypoxia group $(* * P<0.01)$. The protein expression of IL-1 $\beta$ is significantly suppressed with the treatment of $10 \mu \mathrm{M} Z$ Z-YVAD-FMK (**P $<0.01)$. d Immunofluorescence images show the expression of IL-1 $\beta$ ( $B, E$, $\mathrm{H}, \mathrm{K}$, red), lectin ${ }^{+}$microglia ( $\mathrm{A}, \mathrm{D}, \mathrm{G}, \mathrm{J}$, green), and the co-localization of IL-1 $\beta$ and microglia (C, F, I, L). The results also show that high concentration of $\mathrm{CO}_{2}\left(15 \% \mathrm{CO}_{2}\right)$ alone is not enough to increase the expression of IL-1 $\beta$. The expression of IL-1 $\beta$ in hypoxia-activated BV-2 microglia is markedly increased. Additionally, the expression of $\mathrm{IL}-1 \beta$ is further enhanced following treatment of $15 \% \mathrm{CO}_{2}$ in the hypoxic BV-2 microglia. Scale bars: (A-L), 20 um. ns non-significant, IL-1 $\beta$ interleukin-1 beta, HC group high concentration of carbon dioxide group

hypercapnia can enhance activation of NLRP3 inflammasome and production of IL-1 $\beta$ as manifested by the increased protein expression of NLRP3, caspase-1, and IL-1 $\beta$ in hypoxic hippocampus and hypoxia-activated BV-2 cells. There were also interaction effects on cognitive impairment, activation of NLRP3 inflammasome, and the upregulation of IL-1 $\beta$ between hypercapnia treatment and hypoxia treatment.
With relatively fixed ventilator settings, when rats receive mechanical ventilation with $\mathrm{O}_{2}$ concentration of $16 \%, \mathrm{PaO}_{2}$ hovered around $60 \mathrm{mmHg}$. This is consistent with the change of hypoxemia in ARDS. When rats receiving mechanical ventilation with $\mathrm{CO}_{2}$ concentrations of $5 \%, \mathrm{PaCO}_{2}$ was maintained at $60-69 \mathrm{mmHg}$, with $\mathrm{pH}$ at 7.20-7.25 which is consistent with the change of 

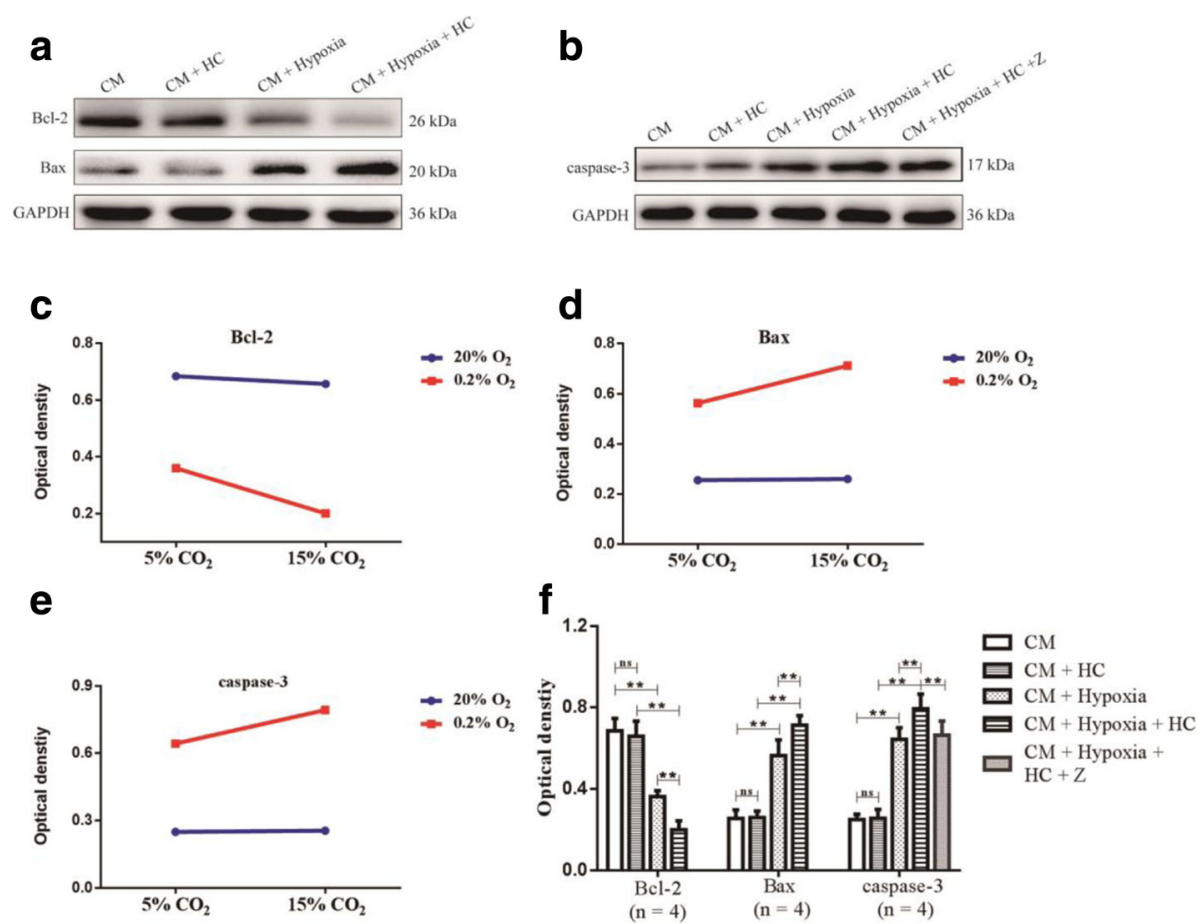

Fig. 11 High concentration of $\mathrm{CO}_{2}$ aggravates apoptosis of cultured neurons via hypoxia-activated microglia $(n=4)$. $\mathbf{a}, \mathbf{b}$ The immunoreactive bands of Bcl-2 (26 kDa), Bax (20 kDa), caspase-3 $(17 \mathrm{kDa})$, and GAPDH (36 kDa). c-e There are significant interaction effects between CM + HC treatment and CM + hypoxia treatment (BCl-2: $P<0.05$; Bax: $P<0.05$; caspase-3: $P<0.05)$. f Simple effects analyses show that the protein expression of $\mathrm{BCl}-2$, Bax, and caspase-3 in $\mathrm{CM}+\mathrm{HC}$ group has no significant difference compared with $\mathrm{CM}$ group ( $\mathrm{ns} P>0.05$ ). The protein expression levels of $\mathrm{BCl}-2$ in $\mathrm{CM}+$ hypoxia group are significantly decreased compared with $C M$ group $\left({ }^{* *} P<0.01\right)$. $C M+$ hypoxia $+\mathrm{HC}$ group has the lowest levels of the protein in comparison with $C M+H C$ group $\left.{ }^{* *} P<0.01\right)$ and $C M+$ hypoxia group $(* * P<0.01)$. In contrast, a significant increase in Bax and caspase-3 expression is observed in $C M+$ hypoxia group compared with CM group (**P<0.01). The levels of Bax and caspase-3 expression in $\mathrm{CM}+$ hypoxia $+\mathrm{HC}$ group is the highest as compared to CM + HC group $\left({ }^{*} P<0.01\right)$ and $C M+$ hypoxia group $\left({ }^{* *} P<0.01\right)$. When $B V-2$ conditioned medium is pretreated with Z-YVAD-FMK, the protein expression of caspase-3 of neurons is significantly suppressed (**P<0.01). CM conditioned medium, HC high concentration of carbon dioxide, Z Z-YVAD-FMK

permissive hypercapnia in ARDS. Although the optimal $\mathrm{PaCO}_{2}$ level is still controversial, in the absence of raised intracranial pressure and/or right cardiac failure, it has been found that $\mathrm{PaCO}_{2}$ up to $70 \mathrm{mmHg}$ with a pH of 7.20 is safe $[27,28]$. The survey showed that most of the physicians prefer to maintain an arterial $\mathrm{pH}$ between 7.21 and 7.25 [29].

Hippocampus is known to be critical for spatial and contextual memory [30]. Thus, Western blot or immunofluorescence staining were used to determine the expression levels of IL-1 $\beta$, NLRP3, and caspase- 1 in the hippocampus in each group. We show here that hypercapnia alone is not sufficient to induce IL- $1 \beta$ production, but NLRP3 inflammasome in hypoxic rat hippocampus microglia can be activated by hypercapnia, as evidenced by the upregulation of caspase- 1 and IL-1 $\beta$. Double immunofluorescence staining has further demonstrated that IL-1 $\beta$ expression was localized in microglia in the hippocampal CA1 region as verified by its co-localization with Iba1, a cellular marker for microglia. In light of the above, it is suggested that hypercapnia can increase the secretion of IL-1 $\beta$ through activating the NLRP3 inflammasome in the hypoxic hippocampal microglia.

To determine the level of apoptosis in hippocampal neurons, Bcl-2, Bax, and caspase- 3 expression was examined by Western blot or double immunofluorescence staining. Along with the overexpression of IL-1 $\beta$, apoptosis of hippocampal neurons increased. There was also an interaction effect on apoptosis of hippocampal neurons between hypercapnia treatment and hypoxia treatment. There was an apparent upregulation of Bax and caspase-3, but a downregulation of $\mathrm{Bcl}-2$ in the hippocampus in rats treated with hypercapnia + hypoxia compared with those treated with hypoxia alone. Double immunofluorescence staining has demonstrated that caspase- 3 expression was localized in neurons in the hippocampal CA1 region as verified by its co-localization with NeuN, a cellular marker for neurons. These results indicated that hypercapnia can aggravate the apoptosis of hypoxic hippocampus neurons.

In vitro results were consistent with in vivo experiments. When microglial cells were exposed to $\mathrm{O}_{2}$ 
concentrations of $0.2 \%, \mathrm{PaO}_{2}$ in supernatants hovered around $60 \mathrm{mmHg}$. When exposed to $\mathrm{CO}_{2}$ concentrations of $15 \%, \mathrm{pH}$ was maintained at 7.20-7.25. There were interaction effects on IL- $1 \beta$ production and activation of NLRP3 inflammasome between $15 \% \mathrm{CO}_{2}$ treatment and $0.2 \% \mathrm{O}_{2}$ treatment. The protein levels of NLRP3, caspase-1, and IL$1 \beta$ were significantly increased by $0.2 \% \mathrm{O}_{2}+15 \% \mathrm{CO}_{2}$ treatment compared with $0.2 \% \mathrm{O}_{2}$ treatment by Western blot and double immunofluorescence study. However, the production of IL-1 $\beta$ was markedly reduced after treatment with $10 \mu \mathrm{M}$ Z-YVAD-FMK, a caspase-1 inhibitor. These results suggest that high concentrations of $\mathrm{CO}_{2}$ can exert an effect in increasing IL-1 $\beta$ production via activating the NLRP3 inflammasome in hypoxia-activated microglia.

To determine if high concentration of $\mathrm{CO}_{2}$ played any role in apoptosis of neurons via hypoxia-activated microglia. Microglia-conditioned medium was used to treat cultured neurons. The expression levels of Bcl-2, Bax, and caspase-3 of neurons were examined by Western blot analysis. There was an interaction effect on apoptosis of primary neurons between high $\mathrm{CM}+\mathrm{HC}$ treatment and $\mathrm{CM}+$ hypoxia treatment. There was an apparent upregulation of Bax and caspase-3, but a downregulation of $\mathrm{Bcl}-2$ in the neurons treated with $\mathrm{CM}+$ hypoxia $+\mathrm{HC}$ compared with those treated with $\mathrm{CM}+$ hypoxia. However, when BV-2 conditioned medium was pretreated with ZYVAD-FMK (a caspase-1 inhibitor), the production of caspase- 3 was markedly reduced. This indicated that inhibition or suppression of NLRP3 inflammasome activation and release of IL-1 $\beta$ might ameliorate apoptosis of neurons. It has been reported that IL-1 $\beta$ can promote apoptosis and contribute to caspase-3 activation [31-34]. In light of present finding, it is suggested that the cascade of IL- $1 \beta$ secretion induced by high concentration of $\mathrm{CO}_{2}$ in microglia may be a risk factor for apoptosis of neurons.

In conclusion, this study has demonstrated for the first time that hypercapnia, besides hypoxia, functions as a modulator of inflammation of the CNS. The present results indicate that hypercapnia-induced IL- $1 \beta$ overproduction by hypoxia-activated microglia can exacerbate neuroinflammation as evident by the increase in neuronal death in the hippocampus. It is conceivable that this would ultimately lead or contribute to the pathogenesis of cognitive impairments. In this regard, hypercapnia induces the secretion of IL- $1 \beta$ via increased activation of caspase- 1 specifically in hypoxia-activated microglia. Supporting this argument is the fact that production of IL- $1 \beta$ is attenuated by inhibiting caspase-1 activation. Thus, the cascade of hypercapnia-induced IL-1 $\beta$ secretion in microglia may be a potential target for treating cognitive dysfunction.

\section{Conclusions}

We show here that hypercapnia can significantly aggravate the cognitive function of hypoxic adult rats. Remarkably, hypercapnia can enhance the activation of NLRP3 inflammasome and release of IL- $1 \beta$ in the hypoxia-activated microglia. Furthermore, the levels of Bcl-2 were reduced, while that of Bax and caspase- 3 were increased in the hippocampal neurons by hypercapnia. Additionally, we have shown that pharmacological inhibition of NLRP3 inflammasome activation and release of IL- $1 \beta$ might ameliorate apoptosis of neurons. In consideration of the present results along with others, it is suggested that hypercapniainduced IL-1 $\beta$ overproduction via activating the NLRP3 inflammasome by hypoxia-activated microglia may exacerbate neuroinflammation, increase neuronal death, and contribute to the pathogenesis of cognitive impairments.

\section{Abbreviations}

ARDS: Acute respiratory distress syndrome; ASC: Apoptosis-associated speck-like protein containing a CARD; CNS: Central nervous system; $\mathrm{CO}_{2}$ : Carbon dioxide; IL-1 1 : Interleukin-1 beta; MWM: Morris water maze; $\mathrm{N}_{2}$ : Nitrogen; NLRP3: NLR family, pyrin domain-containing 3; $\mathrm{O}_{2}$ : Oxygen; $\mathrm{PaCO}_{2}$ : Partial pressure of carbon dioxide; $\mathrm{PaO}_{2}$ : Artial pressure of oxygen; $\mathrm{ROS}$ : Reactive oxygen species

\section{Acknowledgements}

The authors would like to thank Mr. XingHua Hou, Mr. ZhaoYu Wang, Mr. FeiLong Wu, and Mrs. ChunLi Qi for technical assistance.

\section{Funding}

This study was supported by the Natural Science Foundation of Guangdong province (2016A030311043 and 2017A030313691), Pilot Project of Guangzhou Clinical Medical Research and Translational Medicine Center (201508020005), Science and technology project of Guangzhou (155700027), National Natural Science Foundation of China (81701939), and the National Clinical Key Specialty Construction Project Funds (2012-649).

\section{Availability of data and materials}

The datasets used and analyzed during the current study are available from the corresponding author on reasonable request.

\section{Authors' contributions}

DHG carried out assessment of the IL-1 $\beta$, NLRP3, caspase-1, BCl-2, Bax, and caspase-3 expression in the hypoxic hippocampus by Western blotting, collected data, and drafted the manuscript. DYY participated in the design of the study. YRQ and LXS conducted the MWM tests. WQS and ZWH participated in making the hypercapnia/hypoxemia animal model. JWQ participated in assessment of the IL-1 $\beta$ expression in activated microglia in the hypoxic hippocampus by double immunofluorescence. HYL participated in assessment of the caspase-3 expression in hippocampal neurons by double immunofluorescence. HLQ performed the statistical analysis. WMY participated in assessment of the effect of hypercapnia on IL-1 $\beta$, NLRP3, and caspase-1 expression in BV-2 microglia. YF participated in drafting the manuscript. ZHK carried out the design of the study and performed the statistical analysis. All authors read and approved the final manuscript.

\section{Ethics approval}

The animal experiments performed in the present study were approved by the Experimental Animal Care and Use Committee at Jinan University (reference number 20171011001), which conform to the Guide for the Care and Use of Laboratory Animals published by the US National Institutes of Health. All efforts were made to minimize the numbers of animals used and ensure minimal suffering.

\section{Consent for publication}

Not applicable

Competing interests

The authors declare that they have no competing interests. 


\section{Publisher's Note}

Springer Nature remains neutral with regard to jurisdictional claims in published maps and institutional affiliations.

\section{Author details}

'Southern Medical University, 1838 North Guangzhou Avenue, Guangzhou 510515, China. ${ }^{2}$ Department of Emergency and Critical Care Medicine, Guangdong General Hospital and Guangdong Academy of Medical Sciences, 106 ZhongshanEr Road, Guangzhou 510080, China. ${ }^{3}$ Department of Emergency, Dongguan Third People's Hospital, Dongguan, Guangdong, China.

Received: 15 October 2017 Accepted: 27 December 2017 Published online: 05 January 2018

\section{References}

1. Acute Respiratory Distress Syndrome Network, Brower RG, Matthay MA, Morris A, Schoenfeld D, Thompson BT, et al. Ventilation with lower tidal volumes as compared with traditional tidal volumes for acute lung injury and the acute respiratory distress syndrome. N Engl J Med. 2000;342:1301-8.

2. Dellinger RP, Levy MM, Rhodes A, Annane D, Gerlach H, Opal SM, et al. Surviving sepsis campaign: international guidelines for management of severe sepsis and septic shock: 2012. Crit Care Med. 2013;41:580-637.

3. Klein M, Gauggel S, Sachs G, Pohl W. Impact of chronic obstructive pulmonary disease (COPD) on attention functions. Respir Med. 2010; 104(1):52-60.

4. Ozge C, Ozge A, Unal O. Cognitive and functional deterioration in patients with severe COPD. Behav Neurol. 2006;17(2):121-30.

5. Wolters $A E$, Slooter AJ, van der Kooi AW, van Dijk D. Cognitive impairment after intensive care unit admission: a systematic review. Intensive Care Med. 2013;39:376-86.

6. Wilcox ME, Brummel NE, Archer K, Ely EW, Jackson JC, Hopkins RO. Cognitive dysfunction in ICU patients: risk factors, predictors, and rehabilitation interventions. Crit Care Med. 2013;41(Suppl 1):81-98.

7. Hopkins RO, Weaver LK, Collingridge D, Parkinson RB, Chan KJ, Orme JF Jr. Two-year cognitive, emotional, and quality-of-life outcomes in acute respiratory distress syndrome. Am J Respir Crit Care Med. 2005;171:340-7.

8. Mikkelsen ME, Christie JD, Lanken PN, Biester RC, Thompson BT, Bellamy SL, et al. The adult respiratory distress syndrome cognitive outcomes study: long-term neuropsychological function in survivors of acute lung injury. Am J Respir Crit Care Med. 2012;185:1307-15.

9. Norozian FM, Leoncio M, Torbati D, Meyer K, Raszynski A, Totapally BR. Therapeutic hypercapnia enhances the inflammatory response to endotoxin in the lung of spontaneously breathing rats. Crit Care Med. 2011;39:1400-6.

10. Lechan RM, Toni R, Clark BD, Cannon JG, Shaw AR, Dinarello CA, et al. Immunoreactive interleukin-1 beta localization in the rat forebrain. Brain Res. 1990;514:135-40

11. Ban E, Milon G, Prudhomme N, Fillion G, Haour F. Receptors for interleukin-1 (alpha and beta) in mouse brain: mapping and neuronal localization in hippocampus. Neuroscience. 1991:43:21-30.

12. Barrientos RM, Frank MG, Hein AM, Higgins EA, Watkins LR, Rudy JW, et al. Time course of hippocampal IL-1 beta and memory consolidation impairments in aging rats following peripheral infection. Brain Behav Immun. 2009;23:46-54.

13. Dinarello CA. Interleukin-1. Cytokine Growth Factor Rev. 1997:8:253-65.

14. Rangarajan P, Eng-Ang L, Dheen ST. Potential drugs targeting microglia: current knowledge and future prospects. CNS Neurol Disord Drug Targets. 2013;12:799-806.

15. Xiao D, Zhang L. Upregulation of Bax and Bcl-2 following prenatal cocaine exposure induces apoptosis in fetal rat brain. Int J Med Sci. 2008:5:295-302.

16. $Y u Y$, Feng $L, L i ~ J$, Lan $X, A L, L v X$, et al. The alteration of autophagy and apoptosis in the hippocampus of rats with natural aging-dependent cognitive deficits. Behav Brain Res. 2017;334:155-62.

17. Netea MG, Simon A, van de Veerdonk F, Kullberg BJ, Van der Meer JW Joosten LA. IL-1 beta processing in host defense: beyond the inflammasomes. PLoS Pathog. 2010;6(2):e1000661.

18. Pétrilli V, Dostert C, Muruve DA, Tschopp J. The inflammasome: a danger sensing complex triggering innate immunity. Curr Opin Immunol. 2007;19:615-22.

19. Stutz A, Golenbock DT, Latz E. Inflammasomes: too big to miss. J Clin Invest. 2009;119(12):3502-11.
20. Arlehamn CS, Pétrilli V, Gross O, Tschopp J, Evans TJ. The role of potassium in inflammasome activation by bacteria. J Biol Chem. 2010;285:10508-18.

21. Mariathasan S, Newton K, Monack DM, Vucic D, French DM, Lee WP, et al. Differential activation of the inflammasome by caspase-1 adaptors ASC and Ipaf. Nature. 2004;430:213-8

22. Yang W, Zhang $X$, Wang N, Tan J, Fang X, Wang Q, et al. Effects of acute systemic hypoxia and hypercapnia on brain damage in a rat model of hypoxia-ischemia. PLoS One. 2016;11(12):e0167359.

23. Asadbegi M, Yaghmaei P, Salehi I, Komaki A, Ebrahim-Habibi A. Investigation of thymol effect on learning and memory impairment induced by intrahippocampal injection of amyloid beta peptide in high fat diet-fed rats. Metab Brain Dis. 2017;32:827-39.

24. Parajuli B, Sonobe $Y$, Horiuchi $H$, Takeuchi $H$, Mizuno $T$, Suzumura A. Oligomeric amyloid $\beta$ induces $I L-1 \beta$ processing via production of ROS: implication in Alzheimer's disease. Cell Death Dis. 2013:4:e975.

25. Moraes CA, Santos G, de Sampaio e Spohr TC, D'Avila JC, Lima FR, Benjamim CF, et al. Activated microglia-induced deficits in excitatory synapses through IL-1 $\beta$ : implications for cognitive impairment in sepsis. Mol Neurobiol. 2015;52(1):653-63.

26. Han Q, Lin Q, Huang P, Chen M, Hu X, Fu H, et al. Microglia-derived IL-1 $\beta$ contributes to axon development disorders and synaptic deficit through p38-MAPK signal pathway in septic neonatal rats. J Neuroinflammation. 2017;14(1):52

27. Thorens JB, Jolliet P, Ritz M, Chevrolet JC. Effects of rapid permissive hypercapnia on hemodynamics, gas exchange, and oxygen transport and consumption during mechanical ventilation for the acute respiratory distress syndrome. Intensive Care Med. 1996;22:182-91.

28. Hickling $\mathrm{KG}$, Walsh J, Henderson $\mathrm{S}$, Jackson R. Low mortality rate in adult respiratory distress syndrome using low-volume, pressure-limited ventilation with permissive hypercapnia: a prospective study. Crit Care Med. 1994;22:1568-78.

29. Dushianthan A, Cusack R, Chee N, Dunn JO, Grocott MP. Perceptions of diagnosis and management of patients with acute respiratory distress syndrome: a survey of United Kingdom intensive care physicians. BMC Anesthesiol. 2014;14:87.

30. Squire LR. Memory and the hippocampus: a synthesis from findings with rats, monkeys, and humans. Psychol Rev. 1992;99:195-231.

31. Chu H, Xiang J, Wu P, Su J, Ding H, Tang Y, et al. The role of aquaporin 4 in apoptosis after intracerebral hemorrhage. J Neuroinflammation. 2014;11:184.

32. Zhao CQ, Liu D, Li H, Jiang LS, Dai LY. Interleukin-1beta enhances the effect of serum deprivation on rat annular cell apoptosis. Apoptosis. 2007:12(12):2155-61.

33. Cheng W, Wu D, Zuo Q, Wang Z, Fan W. Ginsenoside Rb1 prevents interleukin-1 beta induced inflammation and apoptosis in human articular chondrocytes. Int Orthop. 2013;37(10):2065-70.

34. Lynch AM, Lynch MA. The age-related increase in IL-1 type I receptor in rat hippocampus is coupled with an increase in caspase-3 activation. Eur J Neurosci. 2002:15(11):1779-88.

\section{Submit your next manuscript to BioMed Central and we will help you at every step:}

- We accept pre-submission inquiries

- Our selector tool helps you to find the most relevant journal

- We provide round the clock customer support

- Convenient online submission

- Thorough peer review

- Inclusion in PubMed and all major indexing services

- Maximum visibility for your research

Submit your manuscript at www.biomedcentral.com/submit
) Biomed Central 